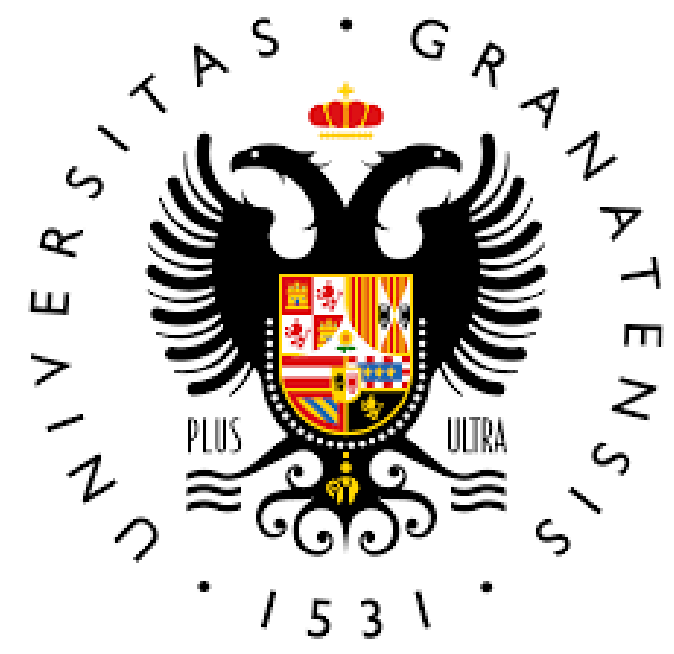

\title{
Análisis de espectros basálticos en Vesta
}

\author{
Belén Martínez Mondéjar
}

TUTOR: René Duffard 
The basaltic surface of the asteroid Vesta says a lot about its origin and the Solar System itself. A surface of these characteristics implies the differentiation of the body, in which the densest materials move to the center of the asteroid and the lighter ones remain on the surface, thus creating a crust, mantle and core. Vesta, according to a large number of studies, suffered this differentiation in the first stages of the formation of the Solar System. When the Solar System was taking its current shape with the migration of the giant planets to the current orbits and the subsequent formation of the terrestrial planets from the initial protoplanetary disk, there was a vestige of those protoplanets that could not form a larger planet. These vestiges took the shape of the main asteroid belt that we know today. For this reason, it is currently thought that the study of these asteroids could help to understand the primordial Solar System, and especially in the case of Vesta, since it is the smallest differentiated body known and can provide clues to the mechanisms of differentiation that affected terrestrial planets in the same way, including ours.

This work focuses on the mineralogical study of Vesta by means of reflectance spectra of its surface and its relationship with HED (Howardite, Eucrite, Diogenite). These are meteorites believed to come from Vesta and small asteroids belonging to its dynamic family with a similar surface spectrum, the Vestoids. To this end, the data provided by the visible and infrared mapping spectrometer VIR of the Dawn spacecraft sent by NASA has been used. From these, the spectrum of 16 points of the surface of Vesta has been obtained and we have worked with parameters derived from them, such as the minimum, centers and depth of the absorption bands I and II of pyroxene. In order to know the proportion of calcium of the minerals that are found there and what depth of the Vesta crust they come from.

\section{$\underline{\text { Resumen }}$}

La superficie basáltica del asteroide Vesta dice mucho sobre su origen y la del propio del Sistema Solar. Una superficie de estas características implica la diferenciación del cuerpo, en la que los materiales más densos se desplazan al centro del asteroide y los más ligeros permanecen en la superficie, creando así una corteza, manto y núcleo. Vesta según gran cantidad de estudios sufrió esta diferenciación en los primeros estadios de la formación del Sistema Solar. Cuando el Sistema Solar fue tomando su forma actual con la migración de los planetas gigantes hacia las órbitas actuales y la posterior formación de los planetas terrestres a partir del disco protoplanetario inicial, quedó un vestigio de aquellos protoplanetas que no pudieron llegar a formar un planeta mayor. Estos vestigios tomaron la forma del cinturón de asteroides principal que hoy día conocemos. Por este motivo, actualmente se piensa que el estudio de estos asteroides podría ayudar a conocer el Sistema Solar primigenio, y especialmente en el caso de Vesta, pues se trata del cuerpo diferenciado más pequeño que se conoce y puede aportar pistas de los mecanismos de diferenciación que afectaron de igual modo a los planetas terrestres, incluido el nuestro.

Este trabajo se centra en el estudio mineralógico de Vesta por medio de espectros de reflectancia de su superficie y su relación con los HED (Howardita, Eucrita, Diogenita), meteoritos que se creen provenientes de Vesta y de pequeños asteroides pertenecientes a su familia dinámica con un espectro de superficie similar, los Vestoides. Para ello se han utilizado los datos proporcionados por el espectrómetro de mapeo visible e infrarrojo VIR de la sonda Dawn enviada por la Nasa. A partir de estos se ha obtenido el espectro de 16 puntos de la superficie de Vesta y se ha trabajado con parámetros derivados de ellos, como son los mínimos, centros y profundidad de las bandas de absorción I y II del piroxeno para conocer desde la proporción de calcio que poseen los minerales que allí se encuentran hasta de que profundidad de la corteza de Vesta proceden. 


\section{Índice}

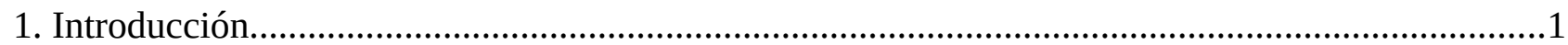

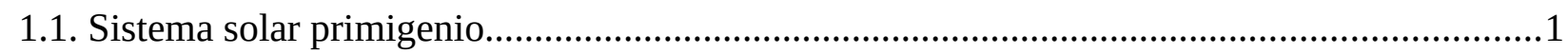

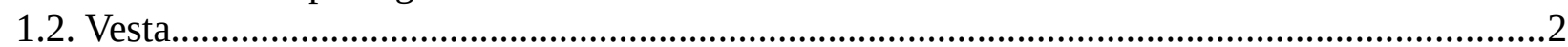

1.3. Identificación de la composición mineralógica..................................................................4

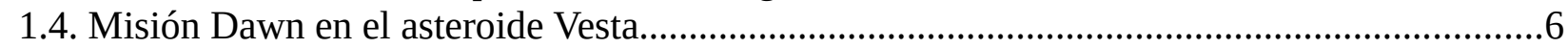

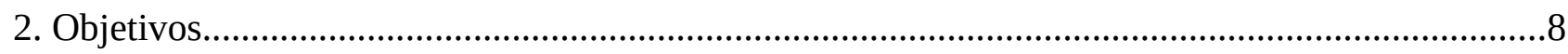

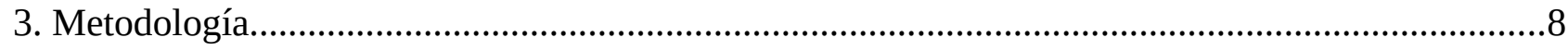

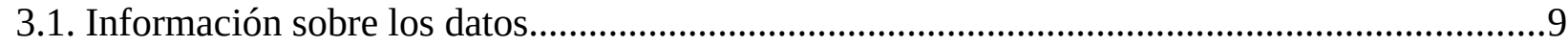

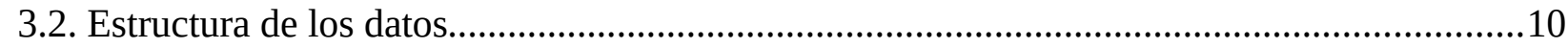

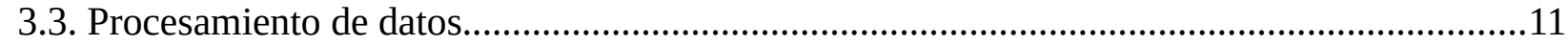

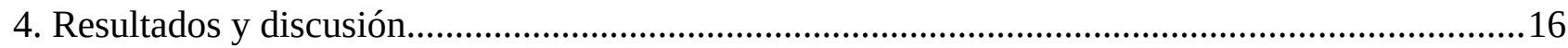

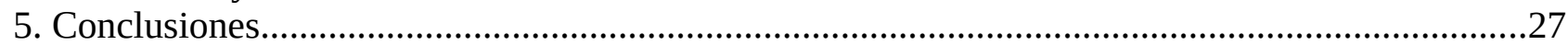

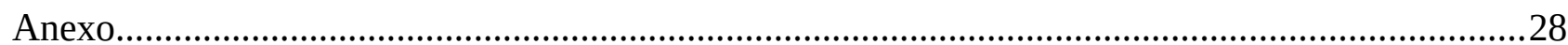




\section{Introducción}

Los modelos actuales de formación del Sistema Solar describen su evolución a partir de una nube fría de gas y polvo, condiciones similares a otras nebulosas conocidas. Con el paso del tiempo el gas y el polvo se disiparon y la nebulosa evolucionó hacia la formación de los planetesimales (cuerpos primigenios), estos a su vez formaron cuerpos más grandes que se calentaron a causa de la desintegración radiactiva y las constantes colisiones (Russell and Raymond, 2011)

Los asteroides que conocemos en la actualidad son los restos de los planetesimales que no pudieron formar un planeta más grande, de modo que los materiales que los componen son los más primitivos. Algunos de estos cuerpos iniciales se calentaron internamente debido a la energía emitida por la desintegración de nucleidos de vida corta como el ${ }^{26} \mathrm{Al}$. Esta evolución térmica dio lugar a la fusión del material condrítico inicial donde el líquido más pesado (Fe-Ni-S) se desplazó hacia el centro del cuerpo y el más ligero (silicatos) quedó en la superfície. Como resultado se obtenía un cuerpo con núcleo metálico denso, un manto más ligero rico en olivino y una corteza basáltica. Esto es lo que se conoce como diferenciación del cuerpo y puede verse en los planetas terrestres, en planetas enanos, satélites naturales como la luna y a veces también en asteroides, como es el caso de Vesta (Duffard, 2012).

\subsection{Sistema Solar primigenio}

Para intentar esclarecer algunas de las preguntas aun sin resolver sobre el Sistema Solar primigenio se diseñó la sonda espacial Dawn, que tenía como objetivo el estudio de los dos cuerpos más masivos del Cinturón Principal de Asteroides, el planeta enano Ceres y el asteroide Vesta. Ya que estudiando estos cuerpos se puede conocer más acerca de como fue la evolución de nuestro Sistema Solar.

El Cinturón Principal de Asteroides, situado entre Marte y Júpiter, es considerado un vestigio del disco protoplanetario que orbitaba el sol antes de que el Sistema Solar tomase su forma actual. De modo que se considera que tanto Vesta como Ceres se formaron al comienzo del nacimiento del Sistema Solar. Pero a pesar de esto, ambos cuerpos se han desarrollado de forma muy distinta. Vesta fue diferenciándose formando un núcleo rico en metales rodeado por un manto rocoso y la superficie se cubrió con una corteza basáltica (Duffard, 2012), mientras que Ceres acumulaba materiales silicatados hidratados y secos en su manto y núcleo respectivamente (McCord and Sotin, 2005).

Vesta es un asteroide rocoso, seco y diferenciado con indicios que sugieren renovación de su corteza. Los HED, meteoritos cuyo origen se atribuye a Vesta, indican que la formación de la corteza y el manto del asteroide tuvo lugar en los primeros $\sim 30$ Ma de la formación del Sistema Solar, mucho antes de que se formaran los planetas terrestres más grandes, como la Tierra. Además, el estudio de estos meteoritos sugiere que la energía necesaria para que se llevase a cabo esta diferenciación de planetesimales fue aportada por elementos radiactivos de vida corta (Russell and Raymond, 2011).

En el caso de Ceres que posee gran cantidad de minerales hidratados, hay recientes evidencias de diferenciación pero no en la misma forma que Vesta, sino con un núcleo interno probablemente formado por silicato seco con una capa externa de silicato hidratado, un manto de silicatos hidratados y una corteza no basáltica (McCord and Sotin, 2005). Este cuerpo es más desconocido 
porque no se poseen meteoritos procedentes de él que restrinjan su formación sobre la escala de tiempo.

Los modelos actuales sugieren que ambos cuerpos se vieron expuestos a colisiones significativas y una evolución térmica desde su formación, lo que puede haber hecho que las características que poseían los primeros $4 \mathrm{Ga}$ de evolución se hayan perdido. Pero estas mismas consideraciones dicen que Vesta no sufrió una extensa fusión superficial, lo que dejaría en su superficie vestigios del bombardeo que caracterizó las primeras etapas de la formación del Sistema Solar (Russell and Raymond, 2011).

Así que, para la investigación de los procesos que ocurrieron en el Sistema Solar primigenio son de suma importancia los siguientes hechos:

- Vesta tiene una evolución térmica inicial que se superpone con el intervalo temporal en el que se formó Júpiter. El modelo preliminar de la evolución térmica de Vesta dice que su manto habría estado fundido en el periodo en el que los planetas gigantes emigraron hacia las órbitas en las que se encuentran en la actualidad, donde Júpiter ejerce varias resonancias poderosas sobre el cinturón de asteroides, lo que excitó a los cuerpos que en ellas se encontraban provocando un mayor número de impactos (Morbidelli et al., 2012). Estos habrían excavado la corteza de Vesta creando fracturas que causaron fenómenos efusivos del manto y la posterior solidificación del material expuesto creando una nueva corteza basáltica, de modo que este proceso habría coincidido con la época de formación de Júpiter.

- La corteza de Vesta no se derritió por completo en ningún momento. Por lo que se puede esperar encontrar en su superficie indicios de los impactos generados en el Cinturón Principal de Asteroides en las primeras etapas del Sistema Solar.

La mayoría de estudios sobre Vesta se han hecho con telescopios desde la Tierra, por lo que el tratar con los datos proporcionados por Dawn otorgará mayor precisión a todos los nuevos estudios que puedan efectuarse. Dicha misión podría ayudar a resolver problemas tan importantes, como son la masa faltante del Cinturón Principal de Asteroides, la escala de tiempo de formación y diferenciación de los planetesimales primordiales, y la migración de los planetas gigantes.

\subsection{Vesta}

Vesta es el segundo objeto, después de Ceres, con más masa del cinturón de asteroides (9\% del total) y el tercero en tamaño con un diámetro de $530 \mathrm{~K}$. Este asteroide podría ser el cuerpo diferenciado más pequeño del Sistema Solar, lo que exhibe a través de su característica corteza basáltica (Duffard, 2012).

La composición de Vesta es muy similar a la de los meteoritos basálticos acondríticos, aquellos que han sufrido una metamorfosis del material condrítico primigenio, caídos en la Tierra, conocidos como HED (Howardita, Eucrita, Diogenita). Los HED están formados por:

- Eucritas: Son rocas de origen magmático que forman la corteza del cuerpo padre del que proceden. Están compuestas principalmente de piroxeno pobre en calcio (ortopiroxeno), pigeonita y plagioclasa rica en calcio. Son las acondritas más comunes. 
- Diogenitas: Es el componente más raro de este grupo. Son rocas ígneas intrusivas (el magma se enfría lentamente en la corteza) y están compuestas principalmente por ortopiroxeno y pequeñas cantidades de olivino y plagioclasa. Proceden de la parte más profunda de la corteza del cuerpo de origen.

- Howarditas: Están formadas principalmente de fragmentos de eucritas y diogenitas, además de condritas carbonaceas. Poseen evidencias de haber sufrido fusión por impacto, lo que indica su origen regolítico en el cuerpo parental (Russell and Raymond, 2011).

Inicialmente se creyó que Vesta era el cuerpo del que procedían los HED, pues sus espectros de superficie, que indican la composición, eran muy parecidos a los de Vesta. Pero con el paso del tiempo fueron apareciendo pequeños asteroides $(5$ a $10 \mathrm{~km}$ ) alrededor de Vesta con una composición superficial y órbitas similares a la de esta . Por lo que pasó a pensarse que Vesta podría no ser el único cuerpo padre de todos ellos. Sino que también podrían provenir de una familia entera similar a Vesta, los Vestoides, asteroides de tamaño reducido con un espectro de tipo V (espectro similar al de Vesta) que se encuentran en la región cercana a Vesta (miembros de su familia dinámica) (Duffard, 2012).

En la actualidad se ha comprobado que los Vestoides provienen de Vesta. Uno de los escenarios más avalados es que se originaran a causa del gran impacto que formó el cráter que cubre el polo sur de Vesta (Rheasilvia). A causa de este impacto parte de los fragmentos fueron expulsados hacia la resonancia 3:1 con Júpiter donde algunos de ellos fueron perturbados hacia órbitas que se cruzan con la Tierra, llegando de esta forma hasta nosotros los HED (De Sanctis et al., 2013).

En la Figura 1 podemos ver el cráter Rheasilvia con su montaña central de $23 \mathrm{~km}$ de altura. Este gran cráter, que cubre casi todo el hemisferio sur de Vesta, tiene un diámetro de $400 \mathrm{~km}$ (McSween et al., 2013). En la región donde se encuentra se han detectado trazas de olivino, lo que sugiere que el impacto que produjo el cráter consiguió llegar incluso al manto de Vesta. Estudios sobre este impacto calculan que expulsó el 1\% de la masa de Vesta al espacio, dando lugar de esta manera a la formación de los Vestoides (Binzel et al., 1997).

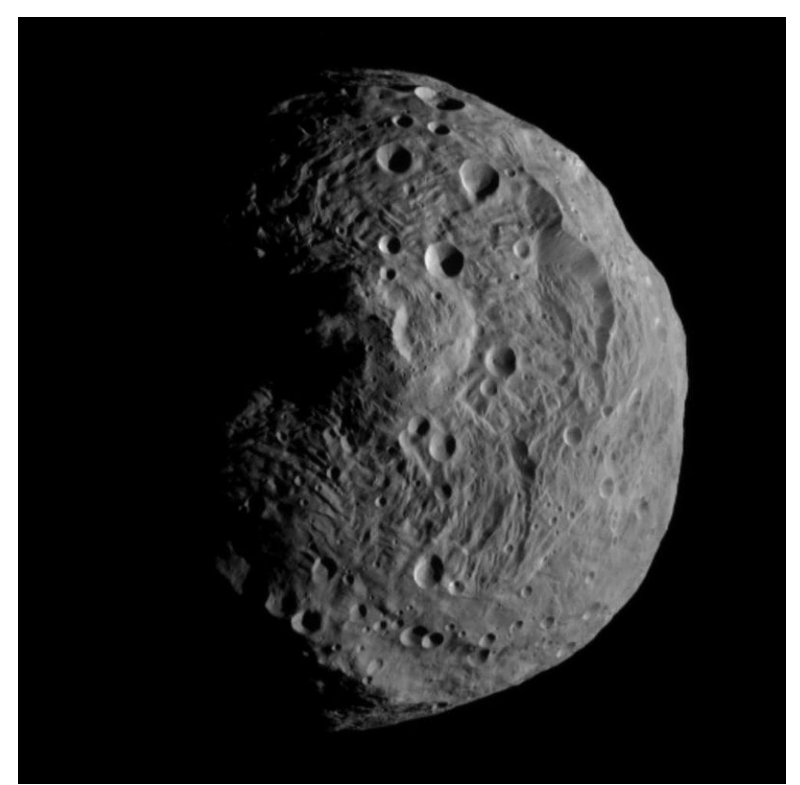

Figura 1: Fotografía del hemisferio sur de Vesta en el que se muestra el cráter Rheasilvia tomada por la sonda Dawn el 16 de Julio de 2011 (NASA - Latest Image of Vesta Captured by Dawn on July 16, 2011, 2011). 
Algunos problemas que se encuentran a los planteamientos anteriores serían, por ejemplo, que el tiempo de exposición a los rayos cósmicos observado en los meteoritos HED no concuerda con el tiempo dinámico de transporte de los Vestoides hasta la Tierra. Pero este problema tiene fácil solución si se considera una deriva lenta de los fragmentos hacia las zonas de resonancia.

Además, algunos de los asteroides de tipo $\mathrm{V}$ en la región cercana a Vesta presentan un espectro con una banda de $1 \mu \mathrm{m}$ más profunda que la mayoría de los Vestoides y la propia Vesta. Lo que hace pensar que provienen de diferentes cuerpos o de diferentes capas de Vesta. Si suponemos que todos los asteroides de tipo $\mathrm{V}$ provienen de Vesta, estas diferencias podrían explicarse con algún gran impacto en Vesta, como el que creó Rheasilvia, que excavara capas internas de la corteza (Duffard et al., 2004).

Otra cuestión que aún esta por resolver es el reciente descubrimiento de un pequeño asteroide basáltico, Magnya, de aproximadamente $30 \mathrm{~km}$ de diámetro, en el cinturón exterior, que ha sido el primero en probarse que no procede de Vesta, ya que se encuentra en una región en la que ningún modelo dinámico podría explicar su origen a partir de Vesta. Tras Magnya han sido encontrados otros pequeños asteroides (menos de $20 \mathrm{~km}$ ) no relacionados con Vesta. Estos asteroides deberían ser trozos de la corteza de un cuerpo diferenciado más grande. Este hecho prueba que Vesta no es el único cuerpo menor diferenciado y debe haber más, o al menos que los hubo en el pasado. Lo que lleva a preguntarse por que si han existido más cuerpos diferenciados en el pasado y han sido destruidos a causa de impactos no se han encontrado también fragmentos del núcleo y el manto. Estas cuestiones aún están en pleno estudio a la búsqueda de respuestas (Duffard, 2012).

Por el momento, el asteroide Vesta es el único gran asteroide basáltico que se puede encontrar en el Sistema Solar. Con aproximadamente 4000 pequeños asteroides en órbitas alrededor del sol similares a la suya procedentes de colisiones con su superficie. El estudio de estos Vestoides puede darnos información sobre la profundidad de la corteza de la que provienen para así conocer mejor el interior de Vesta (Duffard, 2012).

\subsection{Identificación de la composición mineralógica}

Un método para identificar el cuerpo padre de un determinado meteorito es la gráfica isotópica de oxígeno. El oxígeno tiene 3 isótopos estables que se encuentran en unas determinadas proporciones para los materiales que componen cada cuerpo planetario aislado. De manera que con esta gráfica podemos saber si un meteorito procede del mismo cuerpo que otro. El vínculo entre Vesta y los HED se ve respaldado por los datos de isótopos de oxígeno de la mayoría de los HED que indican un origen de estos meteoritos durante eventos tempranos de fusión a escala global (Duffard, 2012).

Pero sin duda la forma más común de obtener información mineralógica de la superficie de un asteroide es a partir de la reflectancia en el espectro visible y el infrarrojo cercano (0.4-2.5 $\mu \mathrm{m})$. A lo largo de este rango espectral existen bandas de absorción que caracterizan qué minerales hay presentes en la superficie. Por ejemplo, la presencia de una banda de absorción en $2.9 \mu \mathrm{m}$ indicaría que el mineral contiene agua.

Los espectros de Vesta inicialmente se obtenían desde la Tierra a partir de telescopios equipados con espectrómetros. Sin embargo, en este trabajo trataremos con los espectros de Vesta obtenidos directamente desde el espacio a través del espectrómetro VIR incorporado en la sonda Dawn lo que implica una enorme mejora en la resolución de los resultados. 
Una vez se obtiene el espectro hay que tener en cuenta que como el asteroide refleja la luz del Sol, los espectros finales deberán ser corregidos extrayendo la componente de luz solar para ver el verdadero espectro del asteroide y así poder conocer su composición. En la Figura 2 podemos ver el espectro final de la superficie de Vesta tomado a través de telescopio.

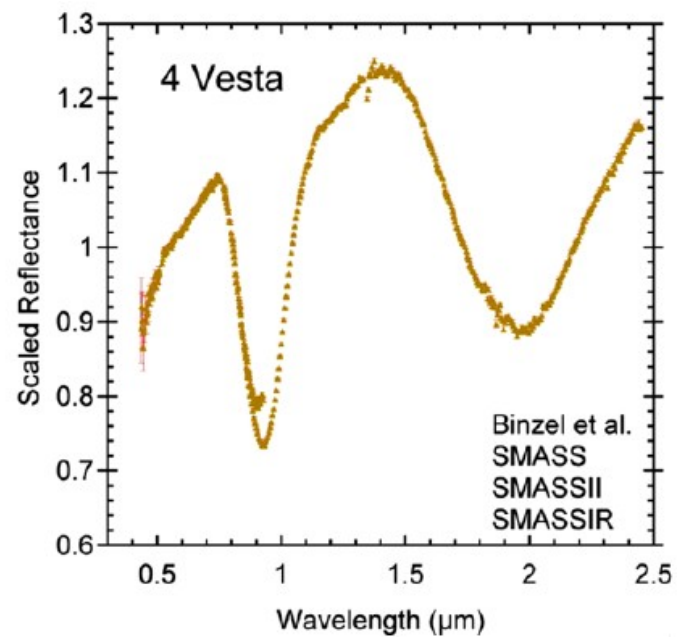

Figura 2: Espectro de Vesta obtenido a través de telescopio por el programa SMASS (Russell and Raymond, 2011).

Una de las bandas de absorción más estudiadas de los espectros de asteroides, son las del piroxeno que se encuentran en torno a $1 \mu \mathrm{m}$ en la banda I y $2 \mu \mathrm{m}$ en la banda II para piroxenos con bajo contenido en calcio. Ambas bandas de absorción pasan a longitudes de onda mayores cuando aumenta la concentración de calcio en su composición (clinopiroxeno).

Otro mineral muy buscado en la superficie de los asteroides, por estar asociada su presencia al manto del cuerpo, es el olivino, que se caracteriza por una banda de absorción compleja centrada en torno a $1 \mu \mathrm{m}$. Por lo que cuando se presenta una mezcla de piroxeno y olivino, la posición de la banda II solo variará con la composición de piroxeno, mientras que la de la banda I es función de la abundancia relativa de cada uno (Duffard et al., 2005). Pueden observarse las características del espectro de estos dos minerales en la Figura 3.

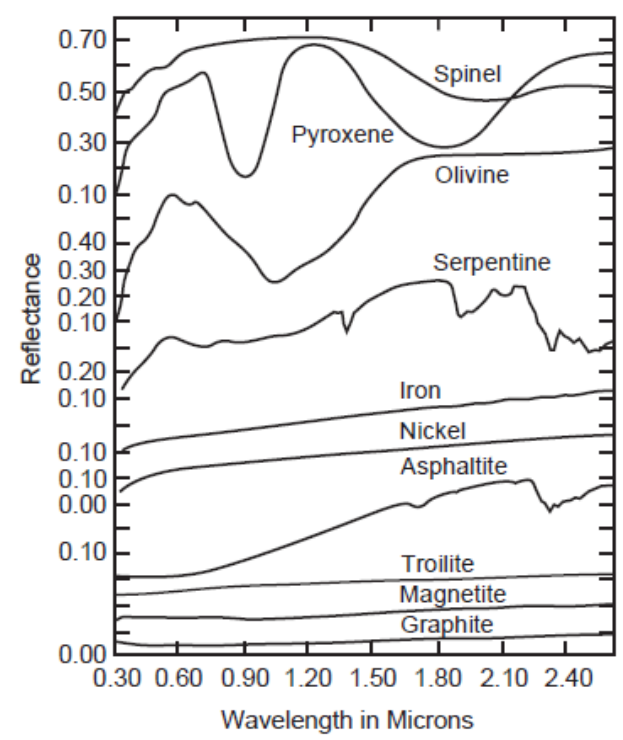

Figura 3: Espectro de reflectancia para distintos materiales (Russell et al., 2004). 
El piroxeno y el olivino son minerales comunes en la formación de rocas del Sistema Solar. Abundan en distintos tipos de meteoritos, como las acondritas y las condritas ordinarias. Al ser posible conocer las características espectrales de los asteroides de forma remota, y puesto que se sabe que los meteoritos proceden de asteroides, se puede realizar una comparación de estos espectros con los espectros de laboratorio de los meteoritos para tratar de identificar el cuerpo del que proceden. A través de este procedimiento es como se ha llegado a la idea de que los HED proceden de Vesta, ya que poseen espectros similares.

En ocasiones hay factores que pueden hacer que los espectros de los HED varíen con respecto al espectro de su cuerpo padre, como son el tamaño del meteorito, la meteorización espacial y la temperatura del laboratorio en el que se analizan, pero en la mayoría de los estudios (Rousseau et al., 2019) se concluye que para asteroides con superficies abundantes en ortopiroxeno, como es el caso de Vesta, la influencia de estos factores es muy pequeña.

\subsection{Misión Dawn en el asteroide Vesta}

La sonda espacial Dawn fue enviada el 27 de septiembre de 2007 desde la Estación de la Fuerza Aérea de Cabo Cañaveral (EEUU) como parte del programa Discovery de la NASA (National Aeronautics and Space Administration). Tuvo como objetivo el estudio de los dos cuerpos más masivos del cinturón de asteroides, Vesta y el planeta enano Ceres. Se cree que estos cuerpos se formaron en los primeros estadios del Sistema Solar, por lo que podrían descubrirnos el Sistema Solar en su edad temprana.

Dawn llegó a Vesta el 16 de julio de 2011, pasó 490 días orbitándolo y recogiendo información, hasta el 5 de septiembre de 2012 que partió camino a Ceres. Comenzó su órbita en torno a este el 5 de marzo de 2015 hasta el final de la misión el 1 de julio de 2016. Finalmente estuvo en una segunda misión extendida en Ceres, para seguir estudiándolo hasta que se le acabó el combustible (Capria, 2018).

Dawn llevaba tres instrumentos para la adquisición de datos sobre los cuerpos, una cámara visible (FC), un espectrómetro de mapeo visible e infrarrojo (VIR) y un espectrómetro de rayos gamma y neutrones (GRaND). También se utilizó un sistema de telemetría que realizaba mediciones radiométricas del campo gravitacional de los asteroides, para así obtener información de su estructura interna (Russell and Raymond, 2011).

Los encuentros con cada uno de los cuerpos se subdividieron en tres fases de mapeo, a diferentes altitudes (Figura 4). Inicialmente la nave entra en una órbita de reconocimiento (survey), donde el instrumento VIR es el dominante, ya que hay una mejor cobertura global para el mapeo espectral. Se adquirieron datos de espectroscopía y mosaicos de imágenes globales durante esta fase para cada uno de los asteroides. A continuación la nave disminuye la distancia al asteroide pasando a una órbita de mapeo de gran altitud (HAMO) donde el instrumento que toma mayor protagonismo es la cámara visible FC. En esta fase se realiza la imagen global de resolución media y se adquiere espectroscopía local de alta resolución. Por último, la nave pasó a la órbita de mapeo de baja altitud (LAMO) donde se realizan los experimentos GRaND y de gravedad y se obtienen imágenes y espectroscopía locales y de alta resolución (Capria, 2018).

La duración de las fases difiere en cada una de las órbitas, la fase survey se sitúa a $2735 \mathrm{~km}$ de la superficie de Vesta y se divide en 7 ciclos con una duración total de 18 días, la HAMO se encuentra a $685 \mathrm{~km}$ y consta de 6 ciclos, cada uno con 10 orbitas y aproximadamente cinco días de duración, 
la LAMO esta a $475 \mathrm{~km}$ de la superficie de Vesta y se divide en 21 ciclos de una semana de duración cada uno y por último, la HAMO 2 esta formada por 6 ciclos más 2 iniciales de 10 órbitas cada uno (PDS: Data Set Information, 2020).

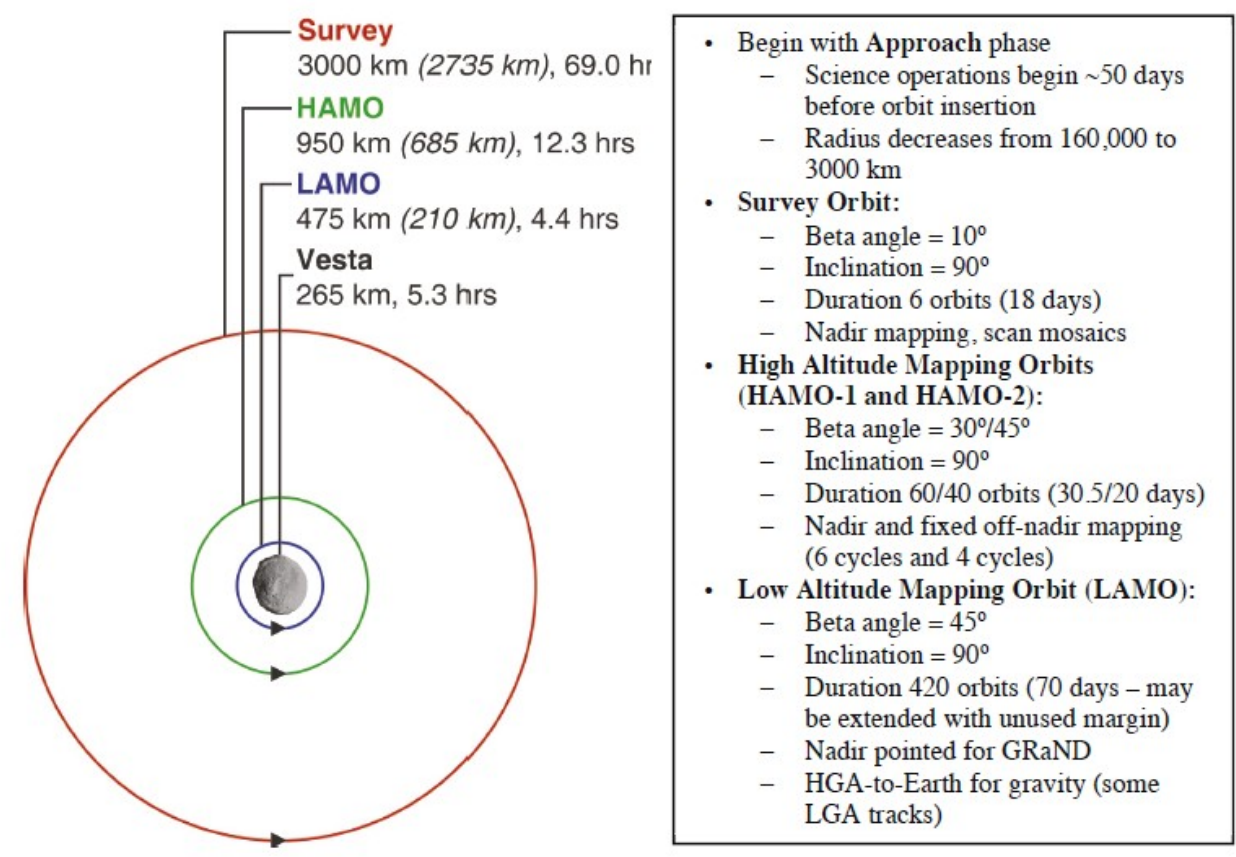

Figura 4: Fases de mapeo de Vesta (Raymond and Raymond, 2015).

La misión que nos concierne tenía como principales objetivos conocer los asteroides a grandes rasgos, como su tamaño, campos gravitacionales, forma, densidad, albedo, orientación del eje de giro, así como características más locales, como son la mineralogía y la topografía. Para ello la Nasa estableció objetivos específicos a cumplir, como obtener imágenes del $80 \%$ de la superficie con buena resolución, realizar un mapa topográfico de la superficie con una resolución horizontal de $100 \mathrm{~m}$ y vertical de $10 \mathrm{~m}$ y obtener 10000 espectros a través del VIR durante las órbitas Survey y HAMO para medir y mapear la composición mineral (Russell and Raymond, 2011).

Los objetivos marcados para cada uno de los instrumentos fueron, para la cámara visible FC:

- Mapear los procesos de las superficies de los asteroides, como se hace al utilizar el registro de cráteres para conocer la cronología que ha seguido la corteza y además poder realizar una estimación de la cantidad de meteoritos que habría en el Sistema Solar primitivo.

- Mapear la topografía y registrar la cantidad de cráteres del cuerpo.

- Buscar polvo y satélites alrededor de los asteroides.

Para el espectrómetro de rayos gamma y neutrones (GraND):

- Determinar la composición elemental principal de $\mathrm{Si}, \mathrm{O}, \mathrm{Fe}, \mathrm{Mg}, \mathrm{Ti}, \mathrm{Al}, \mathrm{H}, \mathrm{Ca}$ y los oligoelementos U, Th, K, Gd y Sm de los dos asteroides.

Pero en este trabajo nos centraremos en el análisis de los datos tomados por el espectrometro VIR, que esta destinado a estudiar la mineralogía de los asteroides, para determinar que minerales forman 
sus rocas y en que abundancia relativa se encuentran. Además de generar mapas de la superficie, medir la temperatura de esta y crear mapas de tipos de rocas y composición mineral que proporcionan información sobre la relación entre las características espectrales locales y globales.

- Los datos aportados por el instrumento VIR ayudarán a corroborar la procedencia de los meteoritos HED a partir de Vesta (Raymond and Raymond, 2015).

El instrumento VIR, combina dos canales de datos, uno en el rango visible (de 0,25-1 $\mu \mathrm{m}$ ) y otro en el infrarrojo (de 0,95-5 $\mu \mathrm{m}$ ). Este instrumento es una modificación del espectrómetro VIRTIS a bordo de la misión Roseta de la ESA (European Space Agency) y está compuesto por un módulo óptico (OM) donde se encuentra una caja electrónica de proximidad (PEM) y por una caja eléctronica principal (ME) (De Sanctis et al., 2011). En el PEM se realiza la adquisición y conversión de los datos científicos. El ME se encarga de controlar el funcionamiento de los dos canales, almacenar los datos y comprimirlos y controlar el enfriador criogénico que mantiene una correcta temperatura del aparato (Russell and Raymond, 2011).

Antes de que Dawn llegara a Vesta, toda la información sobre el asteroide provenía de las medidas de telescopio, los meteoritos HED y modelos teóricos. En rocas de meteoritos y asteroides se exhiben, como hemos visto, bandas de absorción donde la longitud de onda, la forma y la profundidad de estas están determinadas por los minerales y moléculas presentes dentro. Por lo que a partir de los espectros obtenidos de los datos proporcionados por VIR podemos identificar las bandas de absorción para los minerales que se encuentran en las regiones visible e infrarroja cercana con mayor precisión que en el pasado.

\section{Objetivos}

El propósito de este trabajo es el estudio del asteroide Vesta a partir de los recientes datos recogidos por la sonda Dawn en su órbita alrededor de este. Para ello, se procesarán los datos proporcionados por el espectrómetro VIR para visualizarlos en forma de imágenes del asteroide y a partir de ellas, se obtendrá el espectro de reflectancia de ciertos puntos de interés de la corteza de Vesta, tales como: cráteres, laderas... Los espectros obtenidos de esta manera serán procesados y analizados y a partir de ellos se estudiará el tipo de piroxeno, según su composición de calcio, que podemos encontrar en cada punto de la superficie de Vesta elegido. Pero el objetivo principal será el de comparar los resultados espectrales de superficie del asteroide con los de los HED para intentar discernir si Vesta podría ser el cuerpo del que proceden estos meteoritos, analizar la composición y profundidad de Vesta de la que provienen los materiales de las regiones estudiadas, y discutir como influyen en los resultados otros factores como los ángulos de incidencia y emisión de las imágenes o la tendencia de los datos.

\section{Metodología}

Los datos utilizados fueron tomados por el espectrómetro VIR, incorporado en la sonda Dawn, a lo largo de su órbita alrededor de Vesta. En la actualidad se encuentran libres en la página (Vesta VIR, 2020). Pero a pesar de que cualquiera puede acceder a ellos habrá que realizar un considerable trabajo de procesamiento de estos a partir de un software específico para tratamiento de datos adquiridos por misiones espaciales para obtener resultados coherentes a partir de estos. 


\subsection{Información sobre los datos}

Para el procesado de datos se instaló la consola de Ubuntu siguiendo las guías: (Planetary GIS: ISIS3 on Windows 10 WSL Ubuntu (Bash), 2020) y (GitHub - USGS-Astrogeology/ISIS3: Integrated Software for Imagers and Spectrometers v3, 2020). En estas páginas se explica como instalar y trabajar con la consola de Ubuntu y el programa Anaconda que ayuda a trabajar con grandes volúmenes de datos. Una vez hecho esto, se instaló ISIS3 (Software integrado para imágenes y espectrómetros), que es un paquete de sofware de procesamiento de imágenes digitales para manipular imágenes recopiladas por misiones planetarias, en el entorno creado y se descargaron los datos calibrados de la misión Dawn para el espectrometro VIR en sus dos canales, el infrarrojo cercano (IR) de 0,95-5 $\mu \mathrm{m}$ y el visible (VIS) de $0,25-1 \mu \mathrm{m}$ a través de la página: (Vesta VIR, 2020) .

Los datos vienen en la forma:

VIR_sss_11_v_sctime_z

Donde VIR indica el instrumento del que proceden los datos; sss indica el sensor de que se trata, IR o VIS para el espectro infrarrojo o visible respectivamente; 11 indica el nivel de procesamiento, que puede ser 1A (sin calibrar) o 1B (calibrados); v el número de reinicio del reloj; sctime indica el tiempo en el que comienza la toma de datos y z la versión del archivo de datos (que va de 1 a 9).

La extensión es siempre QUB y nos referiremos a ellos como cubos de datos. Un ejemplo de los datos con los que se trabaja sería:

VIR_IR_1B_1_371807186_3.QUB

Donde tendríamos un cubo de datos calibrados en el infrarrojo para la versión 3 del archivo. Los datos de gestión interna asociados se almacenan en una tabla, donde la extensión del archivo que contiene la tabla es .TAB. El nombre de archivo es igual al .QUB que contiene los datos, pero con un "HK" antes del número de versión del archivo. Los datos 1B también incluyen "qubes de calidad". Estos archivos tienen un "QQ" insertado antes del número de versión del archivo. Los qubes de calidad contienen información sobre la calibración del qube de datos asociado. Por último, tendremos los archivos .LBL, que son etiquetas que explican el formato del archivo y los metadatos (Capria, 2018).

\section{$\underline{\text { Calibración }}$}

Habrá tres niveles de calibración de los datos (USGS Isis: Glossary, 2020):

Nivel 0: Fase de procesamiento cartográfico básico que indica que una imagen se ha integrado en ISIS. Estos cubos de nivel 0 suelen ser la entrada de las aplicaciones de calibración radiométrica especificas de la misión que se esta tratando. En el nivel 0 se trata con cubos de imágenes en bruto, no proyectados.

Nivel 1: Para los cubos de nivel 1 la imagen ha sido calibrada radiométricamente, se le ha eliminado la mayoría del ruido e ISIS informa de la geometría de la cámara. La salida de esta calibración será 1a, tras esto el equipo científico del VIR realiza un procesamiento de datos adicional de los que salen los datos de nivel $1 b$. De forma que en el nivel 1 tenemos un cubo calibrado radiométricamente no proyectado. 
Nivel 2: En esta fase de calibración se crea una imagen proyectada en un mapa.

En este trabajo se han utilizado cubos de datos con calibración 1B.

\subsection{Estructura de los datos}

La estructura del cubo de datos viene definida por las coordenadas (muestra, línea, banda) donde las primeras aumentan de izquierda a derecha, las segundas de arriba abajo y la última de adelante hacia atrás (USGS Isis: Logical Cube Format Guide, 2020). Siendo los ejes de muestra y línea planos espaciales y el de banda espectral, como se puede ver en la Figura 5.

Cabe aclarar que aunque hablemos de cubos de datos, en realidad nos referimos a prismas rectangulares, ya que todas las dimensiones no tienen por que ser iguales.

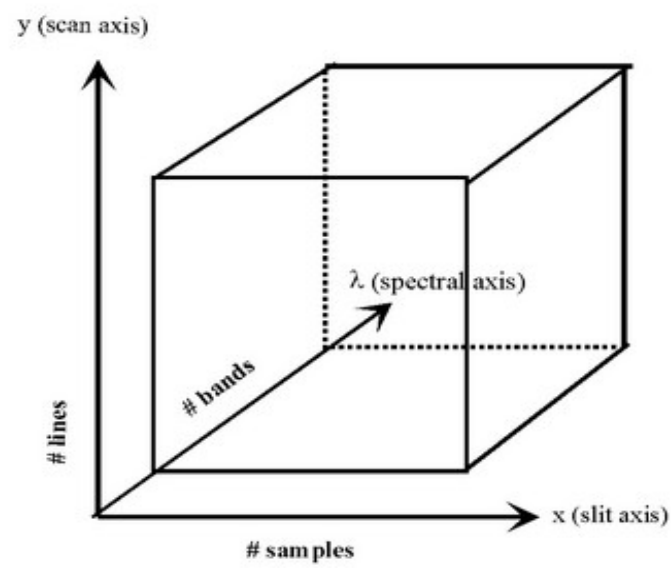

DATA CUBE
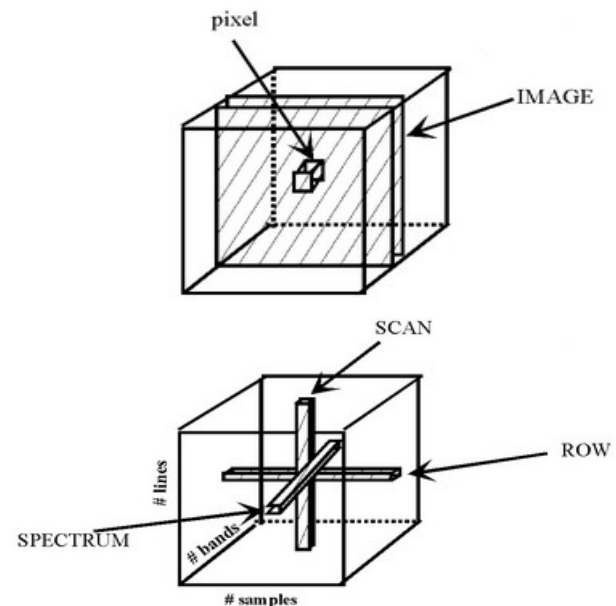

Figura 5: Definición de cubo de datos, imagen y pixel (Capria, 2018).

El instrumento VIR toma una imagen para cada longitud de onda entre 0.25 y $5 \mu \mathrm{m}$. Y el conjunto de imágenes se apila para formar el cubo.

De manera que un cubo de datos es una matriz tridimensional que representa un conjunto de datos frente a las dos coordenadas espaciales y la espectral. Por lo tanto, una imagen es una matriz bidimensional del cubo de datos, definida seleccionando una banda. Y la unidad más pequeña, un pixel, será un elemento de la imagen definido seleccionando las coordenadas espaciales, es decir, una muestra y una línea. Sabiendo todo esto, se puede ver en la Figura 5 que el espectro no es más que una matriz de una dimensión a lo largo del eje espectral (banda) que pasa por el pixel seleccionado. La información de la que luego haremos uso viene contenida en cada uno de estos píxeles (Capria, 2018).

Los datos se organizan y almacenan como archivos PDS (Sistema de Datos Planetarios) con un formato qube. Los qubes PDS son archivos de datos científicos adquiridos de observaciones astronómicas, misiones planetarias de la Nasa y mediciones de laboratorio, estos archivos se componen de tres partes: 
- Etiqueta: Contiene información general sobre el conjunto de datos en formato ASCII.

- Núcleo: Contiene una matriz tridimensional con una dimensión espectral y dos espaciales. Contiene el cubo calibrado en unidades físicas de radiancia $W \mathrm{~m}^{-2} \mu \mathrm{m}^{-1} \mathrm{sr}^{-1}$.

- Plano lateral: Para almacenar telemetría instrumental.

El almacenamiento físico es en BIP (banda, muestra, línea) (Russell and Raymond, 2011).

\subsection{Procesamiento de datos}

Una vez se tuvieron los datos de interés y todas las instalaciones del sofware necesario completadas se siguió el manual (Palmer, 2014) que explica como usar ISIS para leer cubos de datos del VIR (Visual and Infrared Imaging Spectrometer) usado en la misión Dawn. Uno de los primeros pasos es convertir los archivos con formato QUB en cubos de datos adecuados para ser leídos por ISIS (.cub), para ello se pueden usar los comandos dawnvir2isis o pds2isis, este último es más universal pero no mantiene toda la información específica de la cámara, por lo que se perderán algunas características de los datos (como los datos de geometría y definiciones de longitud de onda). Elegimos el primer comando y transformamos los datos de .qub a .cub. Una vez hecho esto ya podemos visualizar los archivos .cub generados en forma de imágenes introduciendo el comando qview en la consola de Ubuntu. Se obtendrán 2 imágenes para la misma región, una en la que su banda es todo el rango visible y la otra el rango infrarrojo cercano.

Tras todo lo anterior se seleccionó un conjunto de las imágenes .cub más interesantes. Por ejemplo, en las laderas de los cráteres para intentar ver material excavado o el material desplazado en las colinas.

En el Anexo podemos encontrar todas las imágenes utilizadas, obtenidas a través de los cubos de datos proporcionados por el espectrómentro VIR en el rango infrarrojo y en el visible. Se mostrarán además los puntos en los que se ha calculado el espectro y la misma región de la superficie de Vesta vista a través de la cámara visible (FC), que proporciona mayor resolución. Por último, se podrá ver también la región de Vesta de la que se han obtenido las imágenes a partir del navegador de imágenes de pequeños cuerpos (Small bodies image browser, 2020) para que el lector las sitúe.

Los cubos de datos de los que se obtienen las imágenes se han tomado en las órbitas HAMO y HAMO 2 (antes y después de bajar a la órbita LAMO). Para la HAMO se ha usado la imagen 1978 del ciclo 2, la 5168 del ciclo 3 y la 7766 del ciclo 4 y para la HAMO 2 las imágenes 1002, 1768 y 2223 del ciclo 0 C0_OFFNADIR1 que consta de 10 órbitas en el hemisferio norte y el polo sur de Vesta.

El nombre de las imágenes proviene de los últimos cuatro dígitos que aparecen en el nombre de cada cubo sin tener en cuenta la versión del archivo, es decir, la imagen obtenida del cubo: VIR_IR_1B_1_371807186_3.QUB sería la 7186. Otro dato a explicar es la línea blanca que aparece en todas las imágenes infrarrojas en el mismo lugar. Esto tan solo se debe a un fallo en el calibrado de la imagen que hace que esos determinados pixeles se saturen (PDS: Data Set Information, 2020). 
Para trabajar con cada una de las imágenes, tendremos que obtener el espectro de los puntos que seleccionemos por medio de la herramienta disponible en el visor de qview, Spectral Plot Tool. Esta herramienta permite obtener el espectro de tantos puntos como queramos en la imagen. Una vez se tiene el espectro, los datos son exportados y abiertos con el programa $\mathrm{R}$ para el procesamiento de los mismos. En la Figura 6 podemos ver la obtención del espectro en un punto de una imagen en el rango infrarrojo usando qview.
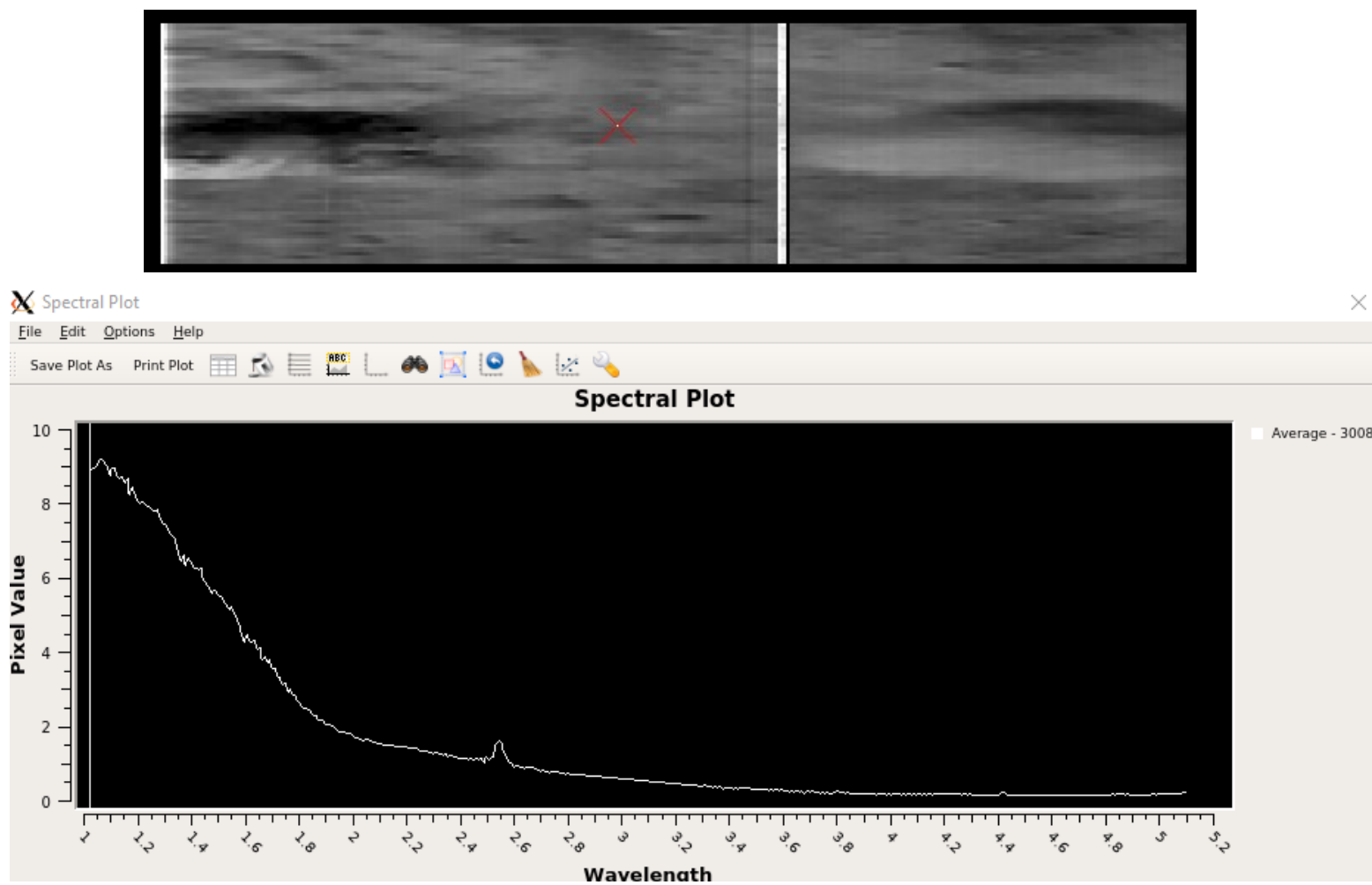

Figura 6: Obtención del espectro del punto seleccionado de una imagen infrarroja a través de qview.

Como se tienen 2 imágenes para cada uno de los cubos, una en el rango visible y otra en el infrarrojo habrá que obtener el espectro de los mismos puntos para las dos imágenes, para ello tan solo hay que registrar en que muestra y linea se sitúa el punto y recrear la selección en la otra imagen. Una vez tenemos los espectros tanto para el infrarrojo como para el visible de los puntos seleccionados en $\mathrm{R}$, los uniremos para obtener el espectro total del punto seleccionado en esa imagen .cub y quitaremos el "ruido" que pueda quedar en la señal, que aparece en forma de picos que se desvían aleatoriamente de lo esperado. Un ejemplo del resultado de este proceso puede verse en la Figura 7 para la imagen 1002. 


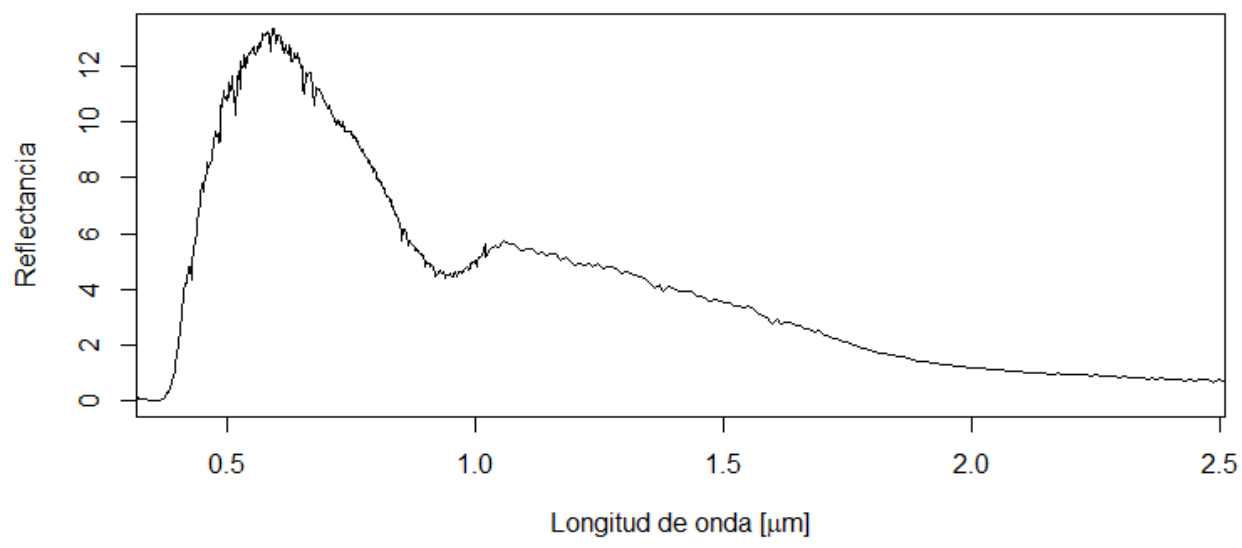

Figura 7: Espectro del punto a de la imagen 1002 sin la corrección solar.

A esta señal tendremos que quitarle la componente espectral solar que se hace muy notoria, ya que como se sabe el espectro de un cuerpo negro, en este caso el sol, toma la forma del área gris de la Figura 8:

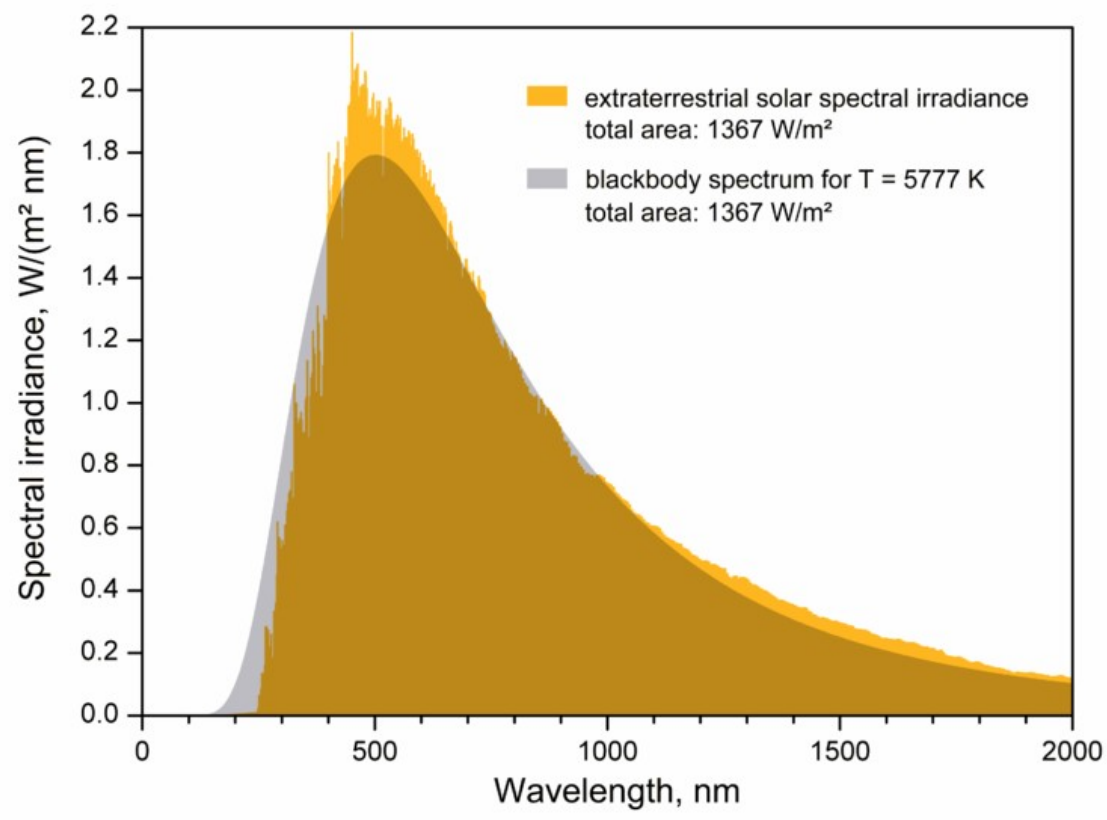

Figura 8: Espectro de un cuerpo negro con temperatura $\mathrm{T}=5777 \mathrm{~K}$ (sol).

Como lo que se quiere conocer es el espectro de Vesta, habrá que dividir el espectro inicial entre el del sol para así, eliminarlo de la señal y quedarnos unicamente con el espectro emitido por la superficie de Vesta. Donde el poder emisivo del cuerpo negro viene dado por:

$$
E(\lambda, T)=\frac{C_{1}}{\lambda^{5}\left(e^{\frac{C_{2}}{\lambda \cdot T}}-1\right)}
$$

Con: 


$$
\begin{gathered}
C_{1}=8 \pi h c=4.9958 \cdot 10^{-24} \mathrm{~W} \cdot \mathrm{m}^{2} \\
C_{2}=\frac{h c}{\mathrm{k}}=1.4385 \cdot 10^{-2} \mathrm{~m} \cdot \mathrm{K}
\end{gathered}
$$

Tras esto normalizamos la reflectancia y queda el espectro de Vesta para el punto seleccionado. En la Figura 9 se puede ver el resultado de lo anterior para el espectro 1002a.

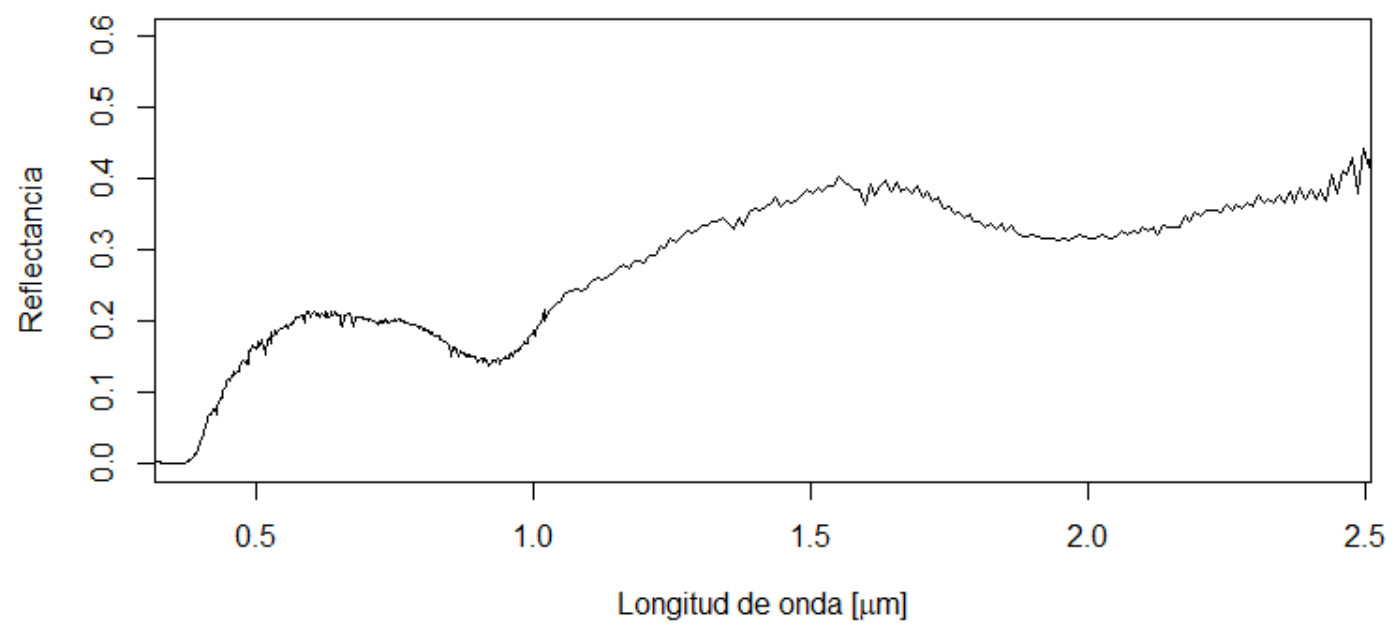

Figura 9: Espectro del punto a de la imagen 1002 tras la corrección solar.

Como se ha explicado, es muy importante la posición del centro de las bandas de absorción en torno a 1 y $2 \mu \mathrm{m}$ para caracterizar la mineralogía a partir de los espectros, pues es donde se encuentran las bandas de absorción del piroxeno, que mostrarán una longitud de onda mayor cuanto más contenido en calcio posean.

Se utilizan dos parámetros para caracterizar esto, el "mínimo de banda" y el "centro de banda" que se definen como la posición de la longitud de onda del punto de reflectancia más baja antes y después de la eliminación del continuo respectivamente (Duffard et al., 2004). Podemos entender como continuo la tendencia de la señal, es decir, la inclinación general que toma. Tras la eliminación del continuo, para lo cual, se ajustan dos líneas rectas a la tendencia que sigue espectro, una para cada banda y posteriormente se divide este entre ellas, la señal seguirá teniendo sus máximos y mínimos pero quedará "enderezada" (Ammannito et al., 2013). Un parámetro a veces también utilizado es la profundidad de las bandas I y II, que se miden como la relación entre el máximo de reflectancia entre la banda I y la banda II y la reflectancia del centro de banda I y la del centro de banda II, respectivamente (Duffard et al., 2004).

La obtención del espectro total para 1002a que se muestra en la Figura 9 se realizó igualmente para un total de 16 puntos de 6 imágenes distintas, el resultado se muestra en la Figura 14.

A partir de estos espectros totales se calculó el mínimo de las dos bandas de absorción de interés, entorno a 1 y $2 \mu \mathrm{m}$. En este trabajo solo nos centraremos en estas bandas de absorción, por lo que podemos cortar el espectro en $2.5 \mu \mathrm{m}$.

Para localizar el mínimo, en primer lugar se utilizó un ajuste parabólico pero no se hallaba con la suficiente precisión, así que finalmente se hizo un ajuste polinomial de grado 5 que proporcionaba 
mayor precisión en los resultados. En la Figura 10 podemos ver la comparación de los dos ajustes para el mismo mínimo.
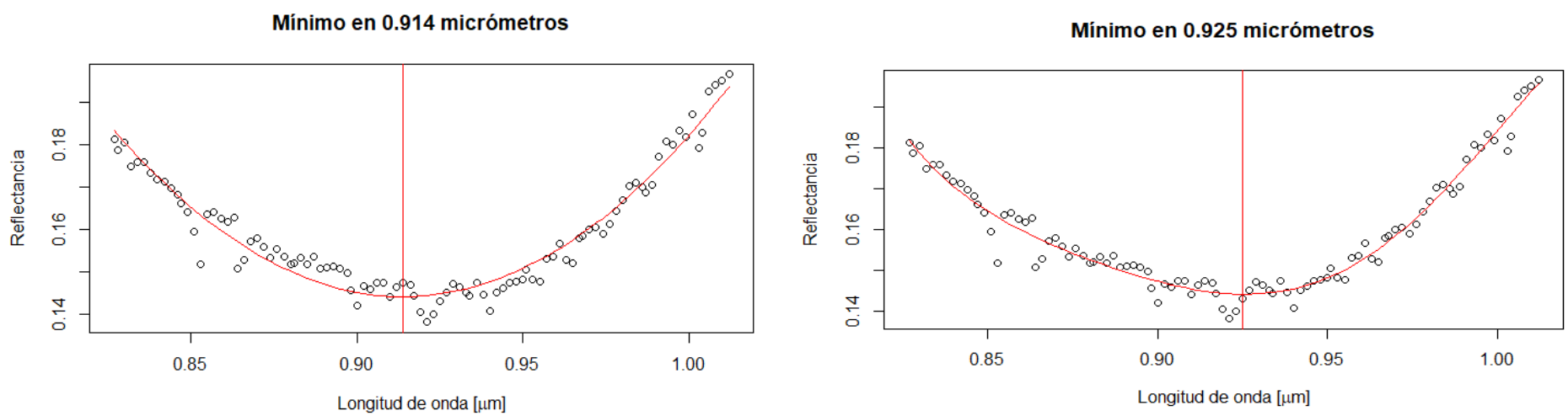

Figura 10: Ajuste parabólico (izquierda) y ajuste polinomial de $5^{\circ}$ grado (derecha).

Se puede apreciar como el ajuste polinomial de $5^{\circ}$ grado reproduce mejor la forma de los datos, lo que hace que el mínimo se desplace hacia la derecha. Este ajuste habrá que hacerlo para las dos bandas de absorción de cada uno de los puntos seleccionados, para así obtener el mínimo de ambas bandas. Para calcular el mínimo y su incertidumbre se han usado tres rangos de longitudes de onda para cada banda. Para la banda 1:[0.808-1.068 $\mu \mathrm{m}],[0.827-1.012 \mu \mathrm{m}],[0.840-0.999 \mu \mathrm{m}]$. Y para la banda 2: [1.692-2.269 $\mu \mathrm{m}],[1.759-2.194 \mu \mathrm{m}],[1.825-2.099 \mu \mathrm{m}]$. De modo que el mínimo se obtenía de la media de los mínimos para los 3 rangos y cada una de las bandas y la incertidumbre a partir de la fórmula de la desviación típica:

$$
\sigma=\sqrt{\frac{\sum_{i}^{N}\left(X_{i}-\bar{X}\right)^{2}}{N}}
$$

Donde $X_{i}$ es el mínimo para cada uno de los 3 rangos, $\bar{X}$ es la media del mínimo para los 3 rangos, y $\mathrm{N}$ es el número de rangos, en nuestro caso $\mathrm{N}=3$.

De esta manera se halla el valor de los mínimos de banda. Pero en la mayoría de los estudios se trabaja con centros de banda, que como se ha explicado en la teoría son los mínimos de las bandas de absorción tras haber quitado el continuo a la señal. Para la eliminación del continuo se ha hallado la posición de los dos máximos cerca de 0.7 y $1.4 \mu \mathrm{m}$ y su correspondiente reflectancia, e igualmente con los puntos en 1.4 y $2.5 \mu \mathrm{m}$ para la segunda banda, nuevamente con un ajuste de $5^{\circ}$. Tras esto se traza una recta del primer máximo al segundo, y otra recta del segundo máximo al punto final del espectro situado en $2.5 \mu \mathrm{m}$. Por último, el espectro es dividido entre las rectas obtenidas, cada una en su respectiva región eliminando de este modo el continuo, o tendencia.

Podemos ver un ejemplo de ello en la Figura 11, que muestra el espectro del punto a de la imagen 1002 tras la eliminación del continuo. Una vez realizado este procedimiento para todos los espectros ya se pueden obtener los centros de banda I y II aplicando de nuevo el ajuste polinomial de $5^{\circ}$ grado a los nuevos mínimos y encontrar así el valor de la longitud de onda en que la reflectancia es mínima para cada banda de absorción. 


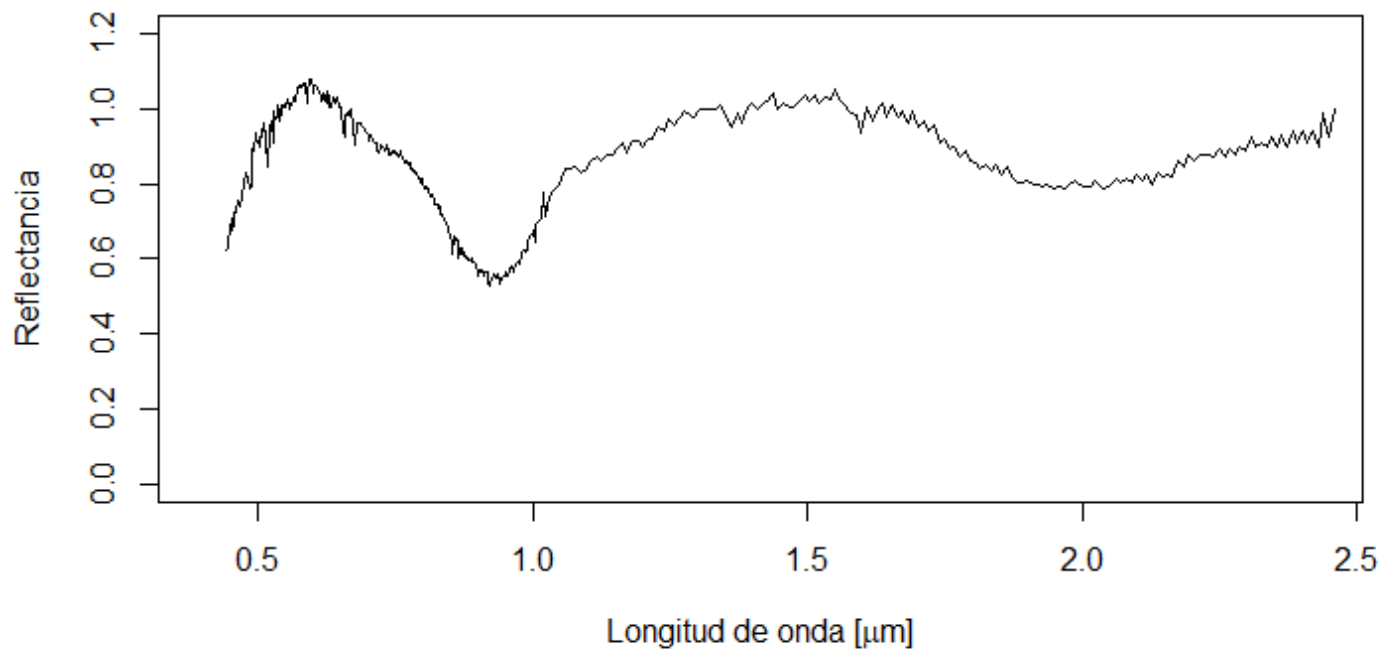

Figura 11: Espectro del punto a de la imagen 1002 tras la corrección solar y la eliminación del continuo.

En la Tabla 1 podemos ver el resultado para todos los mínimos y centros de banda obtenidos con sus respectivas incertidumbres a partir del procedimiento anterior.

\section{Resultados y discusión}

Un análisis de Cloutis y Gaffey (1991) sobre los espectros de reflectancia de ortopiroxenos demostró que los centros de banda se dan, de media, a valores $0.007 \mu \mathrm{m}$ superiores que el mínimo de banda, este resultado se verifica también en (Duffard et al., 2004). En los resultados obtenidos en este trabajo, mostrados en la Tabla 1, se encuentra que los centros de banda se sitúan de media a valores $0.009 \pm 0.003 \mu \mathrm{m}$ superiores que los mínimos de banda, lo que teniendo en cuenta la incertidumbre entra en el rango que estos estudios muestran. 


\begin{tabular}{|l|cccccccc}
\hline Puntos & $\begin{array}{c}\text { Min } \\
\text { Banda I } \\
(\boldsymbol{\mu m})\end{array}$ & $\begin{array}{c}\text { Error } \\
\text { Min I } \\
(\boldsymbol{\mu m})\end{array}$ & $\begin{array}{c}\text { Min } \\
\text { Banda II } \\
(\boldsymbol{\mu m})\end{array}$ & $\begin{array}{c}\text { Error } \\
\text { Min II } \\
(\boldsymbol{\mu m})\end{array}$ & $\begin{array}{c}\text { Centro } \\
\text { Banda I } \\
(\boldsymbol{\mu m})\end{array}$ & $\begin{array}{c}\text { Error } \\
\text { Centro I I } \\
(\boldsymbol{\mu m})\end{array}$ & $\begin{array}{c}\text { Centro } \\
\text { Banda II } \\
(\boldsymbol{\mu m})\end{array}$ & $\begin{array}{c}\text { Error } \\
\text { Centro II } \\
(\boldsymbol{\mu m})\end{array}$ \\
$\mathbf{1 0 0 2 a}$ & 0.925 & 0.001 & 1.964 & 0.008 & 0.934 & 0.001 & 1.979 & 0.008 \\
$\mathbf{1 0 0 2 b}$ & 0.924 & 0.002 & 1.964 & 0.008 & 0.933 & 0.002 & 1.97 & 0.01 \\
$\mathbf{1 0 0 2 c}$ & 0.922 & 0.001 & 1.995 & 0.005 & 0.931 & 0.001 & 2.008 & 0.003 \\
$\mathbf{1 9 7 8 a}$ & 0.921 & 0.001 & 1.986 & 0.005 & 0.929 & 0.001 & 1.995 & 0.005 \\
\hline $\mathbf{1 9 7 8 b}$ & 0.924 & 0.002 & 1.976 & 0.005 & 0.932 & 0.002 & 1.980 & 0.006 \\
\hline $\mathbf{1 9 7 8 c}$ & 0.925 & 0.001 & 1.982 & 0.006 & 0.933 & 0.001 & 1.989 & 0.003 \\
$\mathbf{2 2 2 3 a}$ & 0.919 & 0 & 1.951 & 0.003 & 0.927 & 0.001 & 1.960 & 0.003 \\
$\mathbf{2 2 2 3 b}$ & 0.922 & 0.002 & 1.967 & 0.005 & 0.931 & 0.002 & 1.970 & 0.003 \\
$\mathbf{2 2 2 3 c}$ & 0.921 & 0.001 & 1.954 & 0.006 & 0.929 & 0.001 & 1.967 & 0.005 \\
$\mathbf{5 1 6 8 a}$ & 0.924 & 0.002 & 2.002 & 0.003 & 0.933 & 0.002 & 2.008 & 0.006 \\
$\mathbf{5 1 6 8 b}$ & 0.922 & 0.001 & 1.983 & 0.008 & 0.931 & 0.001 & 1.999 & 0.006 \\
$\mathbf{1 7 6 8 a}$ & 0.924 & 0.002 & 1.980 & 0.006 & 0.933 & 0.002 & 1.992 & 0.009 \\
$\mathbf{1 7 6 8 b}$ & 0.923 & 0.002 & 1.944 & 0.006 & 0.930 & 0.002 & 1.951 & 0.003 \\
$\mathbf{1 7 6 8 c}$ & 0.925 & 0.002 & 1.961 & 0.006 & 0.932 & 0.003 & 1.976 & 0.005 \\
$\mathbf{7 7 6 6 a}$ & 0.924 & 0.003 & 1.992 & 0.003 & 0.931 & 0.003 & 2.002 & 0.003 \\
$\mathbf{7 7 6 6 b}$ & 0.928 & 0.002 & 1.970 & 0.009 & 0.933 & 0.002 & 1.983 & 0.008 \\
\hline
\end{tabular}

Tabla 1. Valores de los mínimos y su error para las bandas I y II.

En los archivos .cub generados se encuentran los parámetros para las imágenes recogidos en la Tabla 2, estos valores serán iguales para las imágenes en infrarrojo y visible, ya que se han obtenido en la misma región y con la misma perspectiva. Para la obtención de las imágenes en infrarrojo y visible de Vesta a través del VIR, la región de estudio recibe un haz, en este caso de radiación infrarroja y luz visible colimada respectivamente, el ángulo con el que este haz incide en la superficie será el ángulo de incidencia (i) y el ángulo con el que esta lo refleja el de emisión (e) .

\begin{tabular}{ccccc} 
Imágenes & Latitud $^{(}$) & Longitud $\left.^{(}\right)$ & $\begin{array}{c}\text { Angulo de } \\
\text { incidencia }^{\boldsymbol{o}} \text { ) }\end{array}$ & $\begin{array}{c}\text { Ángulo de } \\
\text { emisión }^{\boldsymbol{o}} \text { ) }\end{array}$ \\
& 42.312 & 285.980 & 62.876 & 52.386 \\
$\mathbf{1 9 7 8}$ & -35.602 & 60.204 & 37.210 & 12.352 \\
$\mathbf{2 2 2 3}$ & 37.986 & 75.102 & 55.983 & 56.397 \\
$\mathbf{5 1 6 8}$ & -28.478 & 333.056 & 36.756 & 12.156 \\
$\mathbf{1 7 6 8}$ & 35.115 & 269.180 & 56.498 & 51.480 \\
$\mathbf{7 7 6 6}$ & -43.732 & 61.250 & 37.573 & 32.135 \\
\hline
\end{tabular}

Tabla 2: Latitud, longitud y ángulos de incidencia y emisión para cada una de las imágenes utilizadas.

De la Tabla 2 vemos que las imágenes 1002, 2223 y 1768 han sido tomadas en el hemisferio norte de Vesta y la 1978, 5168 y 7766 en el hemisferio sur. Para comprobar esto más visualmente basta con ir al Anexo, donde se muestra la posición en la superficie de Vesta de cada una de las imágenes. Se puede ver como las tres primeras se encuentran cerca del gran cráter de impacto del polo sur de Vesta, Rheasilvia y los otros tres cerca de los cráteres Marcia y Calpurnia del hemisferio norte.

Vesta es de los asteroides con mayor variación de albedo de los objetos del Sistema Solar. Presenta zonas de material oscuro (DM) y en menor proporción de material brillante (BM). Las áreas de BM según los estudios se componen de mayores proporciones de diogenita y howardita en comparación 
con la composición eucrítica general de la corteza. Algunos estudios sugieren que el material oscuro es predominantemente eucrítico, mientras que el material brillante, que se encuentra mayoritariamente en cráteres grandes y jóvenes, es interpretado como material fresco de las capas subyacentes a la superficie que ha sido recientemente excavado por colisiones y está caracterizado por profundidades de banda mayores, en concordancia con su composición, como se muestra en la Figura 12 (Thangjam, 2015).En (De Sanctis et al., 2013) se realiza un estudio sobre los materiales brillantes según su posición en los cráteres, y se concluye que las mayores concentraciones se encuentran en las paredes y la eyección de este tipo de cráteres.

Las profundidades de banda según la composición van de mayor a menor en el orden: diogenita, howardita y eucrita, como se puede ver en la Figura 12.

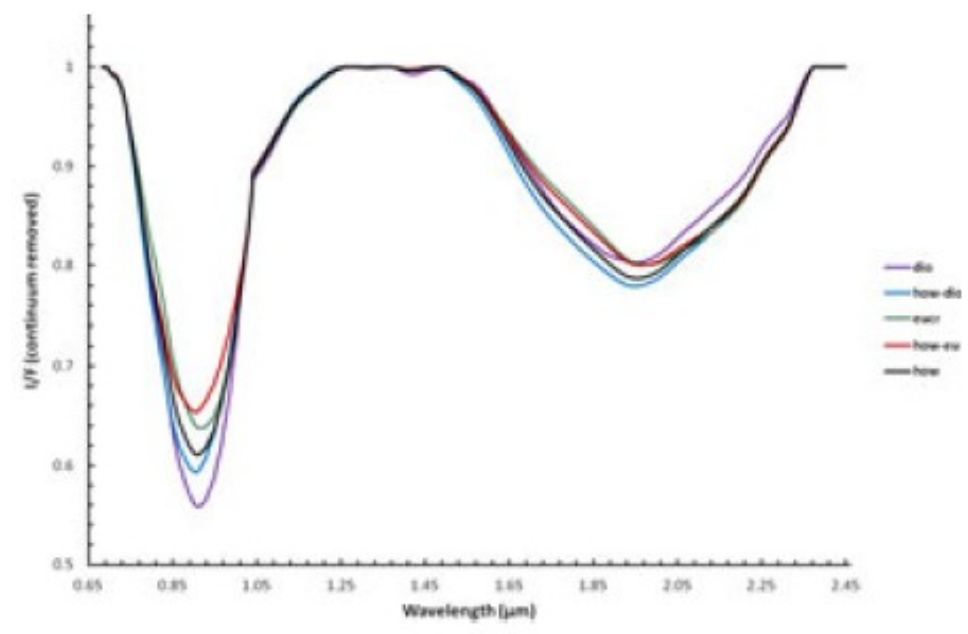

Figura 12: Espectro de reflectancia media obtenida de (De Sanctis et al., 2013), tras eliminar el continuo de: Púrpuradiogenítas, azul-howarditas/diogenitas, verde-eucritas, rojo-howarditas/eucritas y negro howarditas.

En el análisis de los espectros hay que tener muy presente el angulo de incidencia y emisión de las imágenes, pues es un factor determinante en la forma de este. En la Figura 13 se realiza un análisis de estos parámetros a través de 5 gráficas del estudio (Rusch, 2015), cada una de ellas con distinto ángulo de incidencia y sus correspondientes ángulos de emisión asociados. 

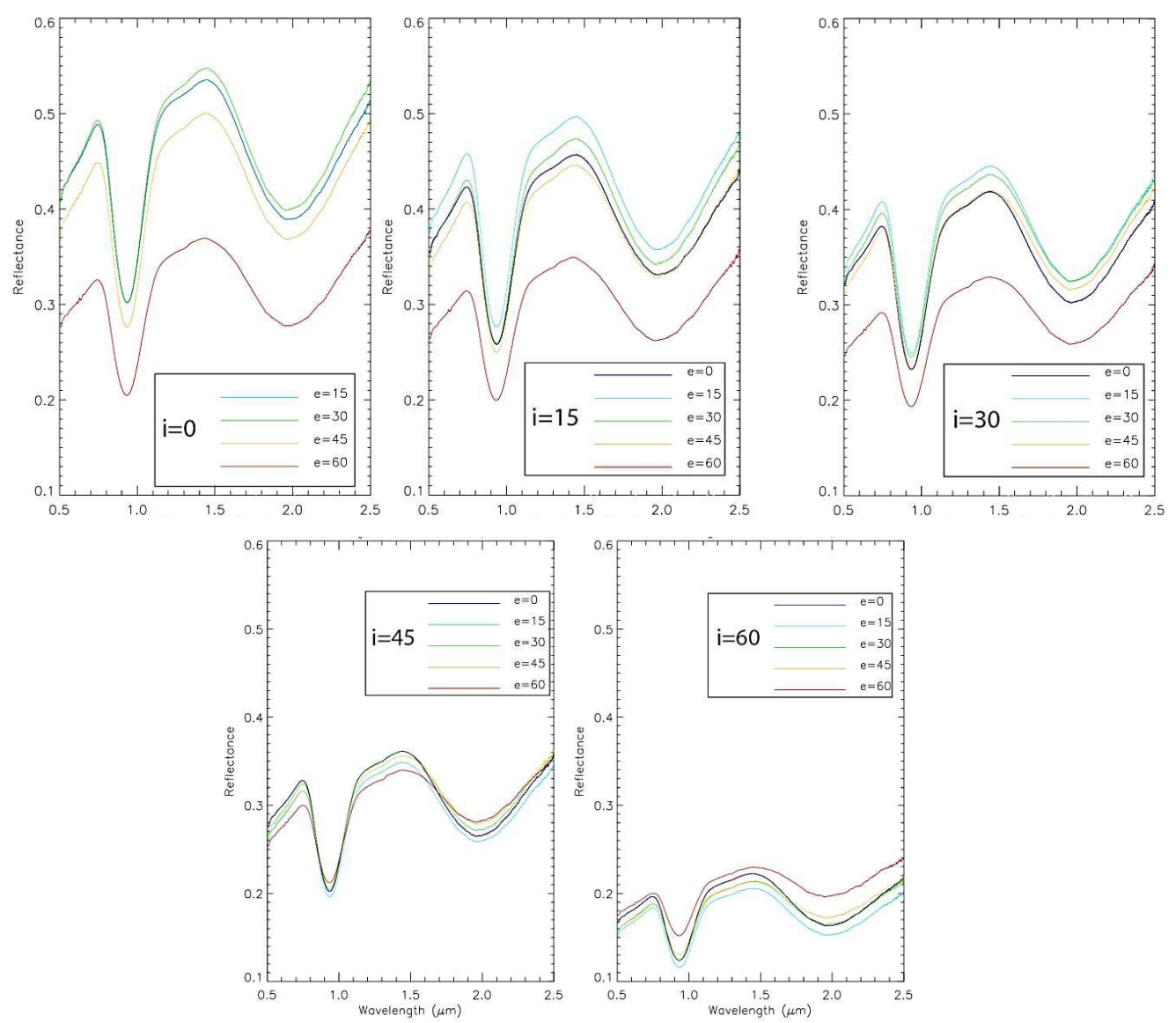

Figura 13. Cada gráfica muestra el espectro de reflectancia con el mismo ángulo de incidencia (i) y distintos ángulos de emisión (e) (Rusch, 2015).

En la Figura 13 se muestran 3 patrones:

1- Al aumentar el ángulo de incidencia disminuye la reflectancia general. Mientras que el aumento de los ángulos de emisión da lugar a un ligero aumento seguido de una disminución de la reflectancia.

2- La reflectancia disminuye más fuera de las bandas de absorción, lo que propicia una disminución de las profundidades de banda conforme aumentan los ángulos de incidencia y emisión.

3- No cambia la posición de los mínimos de las bandas de absorción.

Se puede concluir que el espectro de reflectancia se ve influenciado por la geometría de observación, es decir, sus ángulos de incidencia, emisión y fase.

Tendremos que aplicar estos criterios a los espectros totales de los puntos analizados en este trabajo, mostrados en la la Figura 14. 


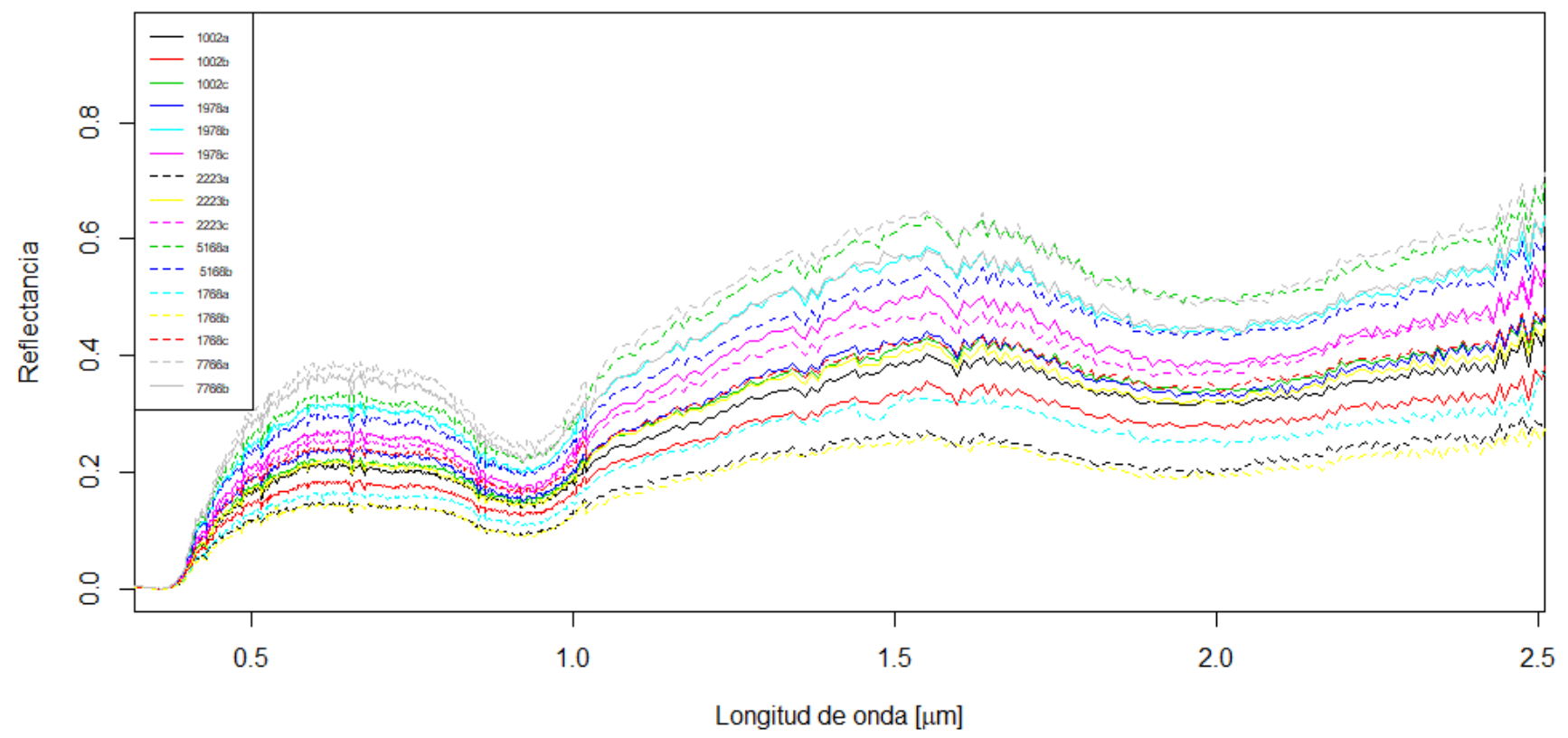

Figura 14: Espectros totales de todos los puntos estudiados.

Si analizamos las imágenes con las que se han trabajado teniendo en cuenta los valores de la Tabla 2 y la Figura 13 se obtiene la Tabla 3 que muestra en que caso de la Figura 13 estaría cada imagen. Donde la columna gráfica se refiere a que gráfica de la Figura 13 representa mejor el ángulo de incidencia en cada caso y la columna línea a cual de los espectros de la gráfica seleccionada representa mejor el ángulo de emisión de la imagen.

\begin{tabular}{|c|c|c|}
\hline Imagen & Gráfica & Línea \\
\hline $\mathbf{1 0 0 2}$ & 5 & Amarillo- Roja \\
$\mathbf{1 9 7 8}$ & $3-4$ & Azul \\
$\mathbf{2 2 2 3}$ & 5 & rojo \\
$\mathbf{5 1 6 8}$ & $3-4$ & Azul \\
$\mathbf{1 7 6 8}$ & 5 & Amarillo \\
$\mathbf{7 7 6 6}$ & $3-4$ & Verde \\
\hline
\end{tabular}

Tabla 3: Se muestra en que situación de las representadas en la Figura 13 se encuentra cada imagen estudiada.

Si imponemos la referencia en una incidencia de $30^{\circ}$ y una emisión de $0^{\circ}$ como se hace en la mayoría de estudios (De Sanctis et al., 2013), se pueden ver claramente dos grupos diferenciados. Los que aproximadamente se encuentran en la referencia: 1978, 5168 y 7766 y los que tienen un ángulo de incidencia mucho mayor $\left(\sim 60^{\circ}\right)$ : 1002, 1768 y 2223. Si se observa la Figura 13, se ve que para este segundo grupo, que se asemeja a la gráfica 5 , los espectros son más aplanados debido al ángulo de incidencia y no a la naturaleza de estos. Ya que en la Figura 17 se puede ver que justamente $1768 \mathrm{~b}$ y $2223 \mathrm{a}$ son los puntos que más a la izquierda se encuentran y por lo tanto mayor proporción de howardita tendrían, que se asocia a mayores profundidades de banda que las eucritas puras como se muestra en la Figura 12. Por lo que estos espectros aplanados para el segundo grupo tan solo son debidos a su mayor ángulo de incidencia. 
Ahora bien, dentro de los tres espectros de 2223 por ejemplo, vemos en la Figura 17 que el punto 2223a es el que más cerca de las howarditas se encuentra, mientras que los otros dos se hallan en el rango de las eucritas como la mayoría de los otros puntos. De esta observación se deduce que el espectro que mayor profundidad de bandas debería tener de los tres sería el 2223a, lo que no se observa en la Figura 14. Este efecto solo se debe a la propia definición de profundidad de banda, que dice que la profundidad de las bandas I y II se miden como la relación entre el máximo de reflectancia entre la banda I y la reflectancia del centro de banda I y la de la banda II con la del centro de banda II, respectivamente, por tanto una vez que se implican centros de banda hay que eliminar el continuo. Si se esta en lo cierto, al comparar los espectros 2223a, 2223b, 2223c tras eliminar el continuo se obtendrá que el 2223a es el que tiene las bandas de absorción más profundas.

En la Figura 15 se puede ver que, efectivamente, esto se cumple.

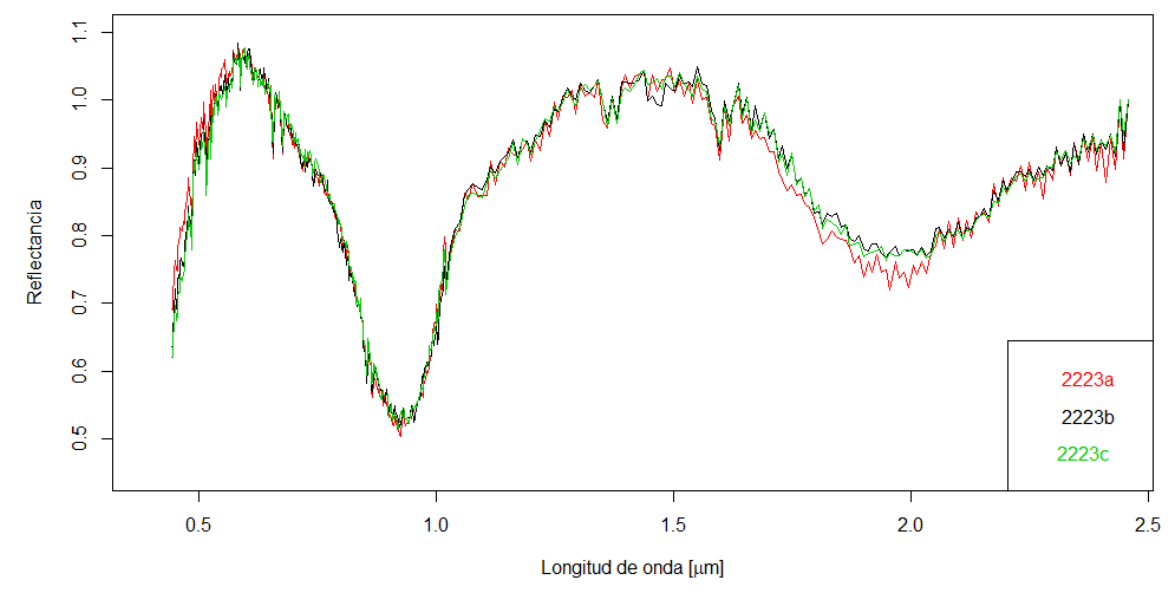

Figura 15: Comparación de los espectros de la imagen 2223 tras la eliminación del continuo.

Igualmente en la Figura 16 para los espectros de la imagen 1768, el 1768b es el que mayor profundidad de banda exhibe, lo que se encuentra en concordancia con el hecho de que sea el punto que más a la izquierda se encuentra de toda la Figura 17.

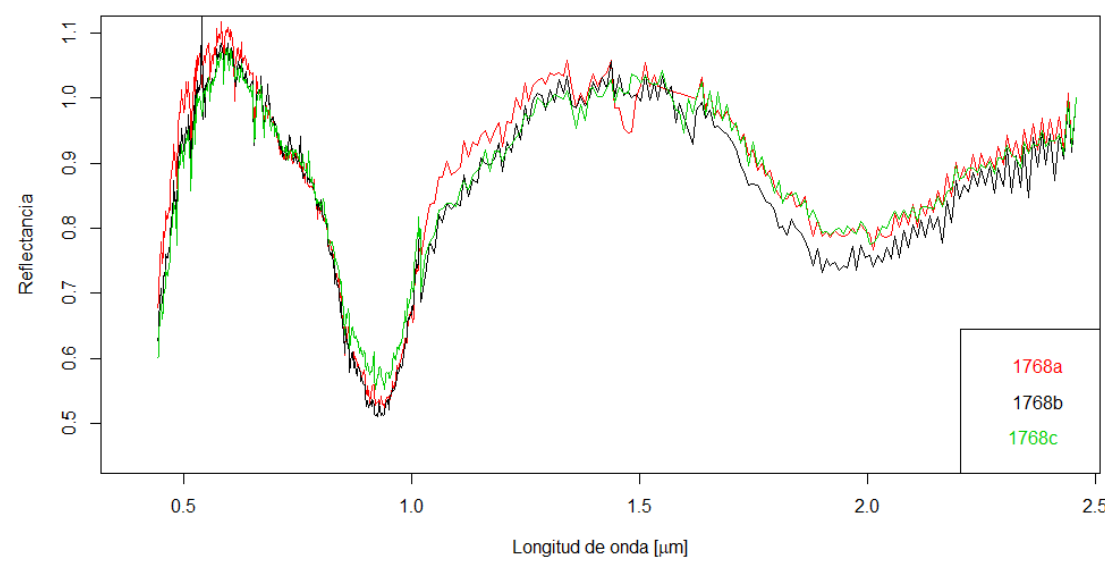

Figura 16: Comparación de los espectros de la imagen 1768 tras la eliminación del continuo. 
En ambos casos la banda II es más profunda para los puntos más cercanos a las howarditas y en el segundo caso también se observa este efecto ligeramente para la banda I.

Pero el parámetro más importante y utilizado para caracterizar la mineralogía de los cuerpos a través de sus espectros son los centros de banda, que en este trabajo se muestran en la Tabla 1. Se va a proceder a dos análisis a partir de estos parámetros. En primer lugar en la Figura 17 se compara los centros de banda obtenidos en el análisis de este trabajo con los de los meteoritos HED y algunas otras acondritas descritos en (Duffard et al., 2005).

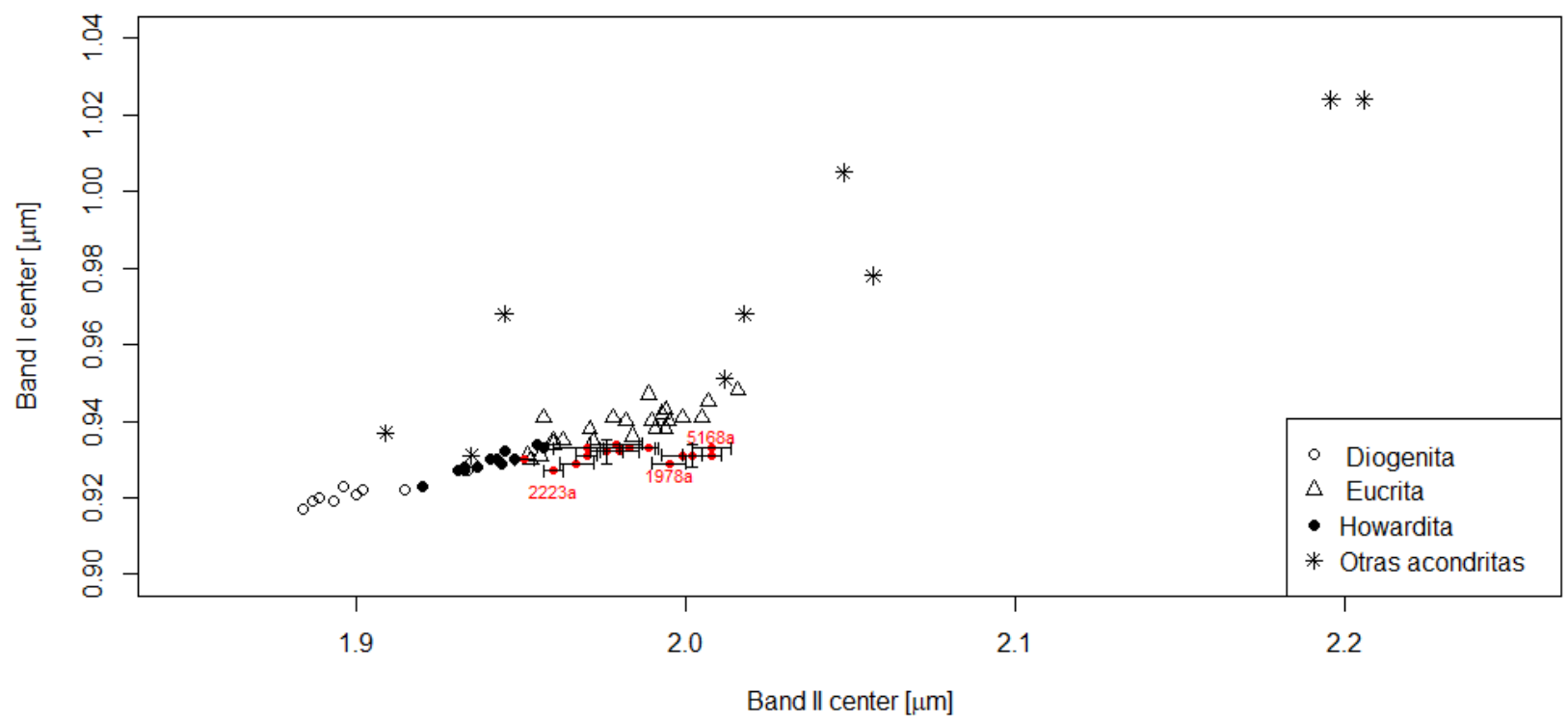

Figura 17: Centro de banda I frente al centro de banda II donde se muestran los puntos estudiados con sus errores y los HED.

La distribución de los HED está formada por las eucritas en la parte superior derecha de la región de la gráfica, las diogenitas en la zona inferior izquierda y las howarditas entre las dos anteriores, pues estas están compuestas de una mezcla de las primeras.

Los HED pueden dar información sobre la profundidad del cuerpo padre de la que proceden, ya que los modelos describen una corteza inferior de diogenita y la superior de eucrita. Al comparar estos HED con nuestros resultados somos capaces de conocer que minerales hay en la región que estamos estudiando y por tanto también si se trata de material fresco expuesto por colisiones o no. En nuestro caso vemos como el conjunto general de los puntos se distribuye en la región de las eucritas, lo cual era de esperar ya que, como se ha dicho en la teoría son las acondritas más comunes en la superficie.

Dentro del conjunto de puntos se observa que hay un par que se encuentran más a la izquierda que el resto, al final de la región de las howarditas, el 2223a y el 1768b. Según lo explicado arriba estos puntos deberían pertenecer a lugares en la superficie de Vesta con material más reciente y de capas algo inferiores que los demás. Si nos fijamos en el Anexo, en las Figuras 5 y 6 se comprueba que ambos puntos pertenecen a paredes de grandes cráteres que no parecen haber sido cubiertos por sedimentos, lo que lleva a pensar que son relativamente jóvenes. Este resultado concuerda con el estudio (De Sanctis et al., 2013) comentado anteriormente, que concluye que las mayores concentraciones de material brillante y por tanto fresco se encuentran en las paredes de los grandes cráteres jóvenes. 
Además se puede comparar este resultado con el de otros estudios, como el de (McSween et al., 2013) que se muestra en la Figura 18. En dicha figura aparecen eucritas cumulativas y basálticas, ambas rocas ígneas, pero mientras que las primeras se encuentran típicamente en intrusiones ultramáficas, las segundas son de origen extrusivo.

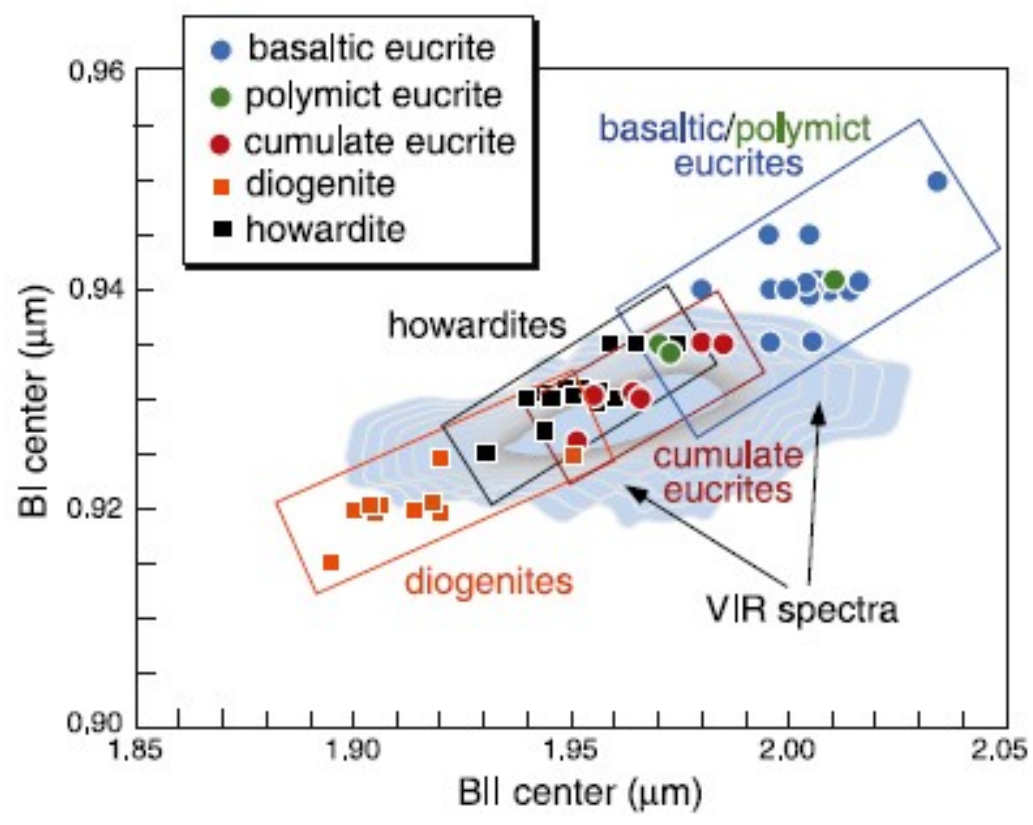

Figura 18. El área azul representa la posición de los centros de banda de los espectros del VIR sobre la que se impone el diagrama de posición de los HED(McSween et al., 2013).

En este estudio la posición de los centros de banda obtenidos a partir del espectrometro VIR de la sonda Dawn muestran una mayor afluencia entorno a las eucritas cumulativas y las howarditas lo que entra en concordancia con los resultados de este trabajo.

Estos resultados abalarían que el origen de los HED fuese Vesta o algunos de los pequeños asteroides procedentes de esta (Vestoides), pues como se puede ver, los resultados obtenidos por el VIR son bastante parecidos a los de los HED, salvo una pequeña diferencia en la banda I que da resultados para el VIR con una pendiente ligeramente distinta que en los resultados de los HED. Pero esta pequeña diferencia podría deberse a algunas características que alteran levemente los resultados como son el tamaño del meteoritos, la meteorización espacial y la temperatura del laboratorio donde se analizan.

En segundo lugar, se ha comparado la posición de los centros de banda obtenidos con la de mezclas de distinta proporción de ortopiroxeno y clinopiroxeno en la Figura 19, obtenidas nuevamente de (Duffard et al., 2005). En la que se demuestra lo ya enunciado en la teoría, que la corteza de Vesta esta mayoritariamente compuesta por piroxenos de bajo calcio (ortopiroxenos). Se destaca también como los puntos más eucríticos tienen mayor concentración de calcio que los más cercanos a las howarditas. 


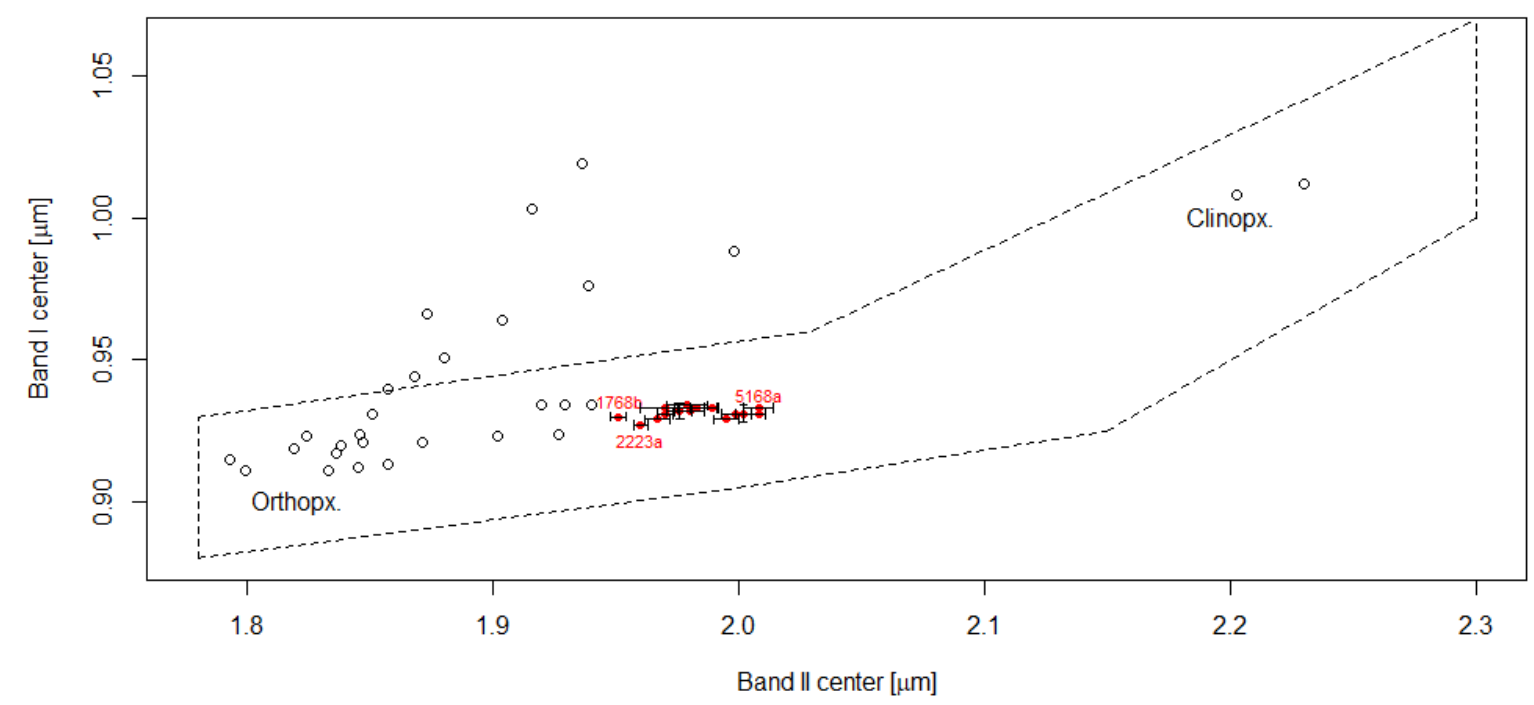

Figura 19: Centro de banda I frente al centro de banda II donde se muestran los puntos estudiados con sus errores y piroxenos de bajo calcio (Ortopiroxenos) y alto calcio (Clinopiroxenos).

Tras todos los resultados comentados faltaría un pequeño análisis sobre las imágenes que no se han mencionado. En primer lugar, para la imagen 1978 podemos ver en el Anexo que el punto a se encuentra en el centro de un cráter, el b pertenece a la pared de este y el c en las afueras de él. En la Figura 20, que resalta los centros de banda para esta imagen, se observa como nuevamente se cumple que el punto perteneciente a la pared del cráter es el que más cerca se encuentra de las howarditas, debido a que se trata de material escavado durante la colisión que produjo el cráter. En segundo lugar en cercanía a las howarditas se encuentra el punto c, perteneciente a las afueras del cráter, que este punto se encuentre más a la izquierda de la gráfica de los HED podría significar que se trata de material eyectado a causa del impacto pero la diferencia entre los centros de banda de 1978 a y 1978 c es tan pequeña en comparación con el error que sería difícil afirmarlo.

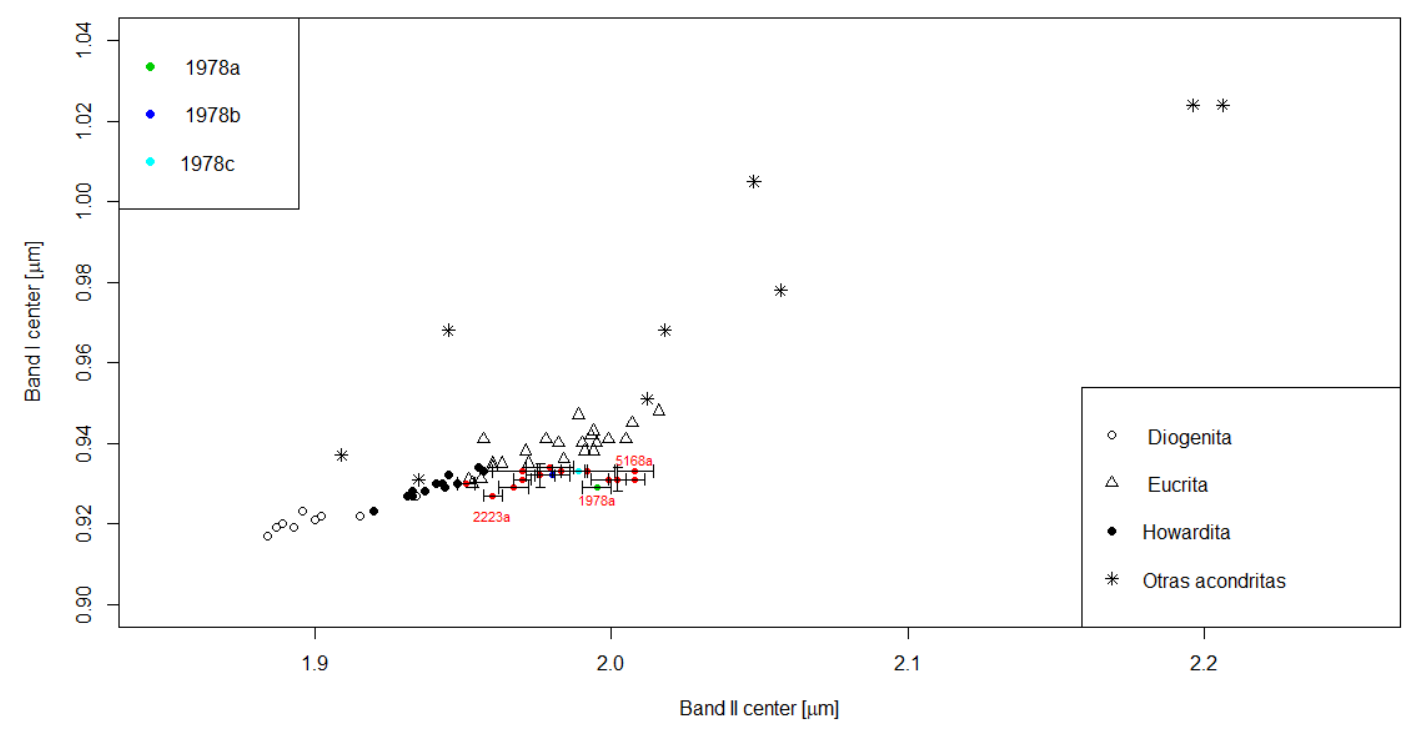

Figura 20. Centro de banda I frente al centro de banda II donde se muestran los puntos estudiados con sus errores y los HED. Se encuentran resaltados los puntos pertenecientes a la imagen 1978. 
En el caso de la imagen 5168 se puede ver en el Anexo que el punto a corresponde al centro de un cráter grande y el $\mathrm{b}$ al centro de otro más pequeño. En esta imagen habría sido más útil centrarse en el primer cráter y haber elegido el segundo punto en la pared de este, para comprobar la diferencia entre ambas regiones. Podría extrañar a algunos lectores que en el centro de los cráteres no se encuentre material tan brillante o fresco como en las paredes de estos. Esto tiene sentido, ya que el material de capas profundas que podría quedar al descubierto en esta región con el impacto acaba ocultándose con material suelto que cae al cráter. Se observa en la Figura 21 como la posición de los centros de banda para ambos puntos es muy pequeña, por lo que no habrá a penas diferencias mineralogicas entre las regiones.

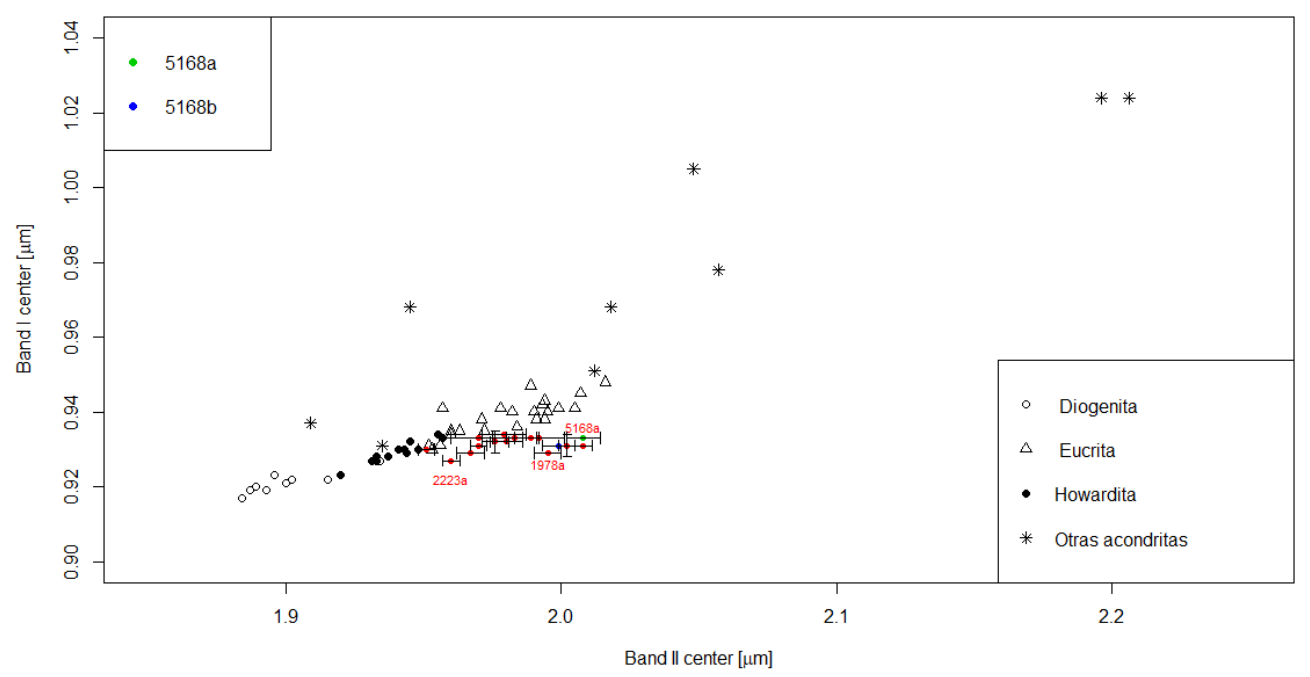

Figura 21. Centro de banda I frente al centro de banda II donde se muestran los puntos estudiados con sus errores y los HED. Se encuentran resaltados los puntos pertenecientes a la imagen 5168.

La imagen 7766 es un poco diferente al resto, en esta ocasión se observan estructuras que sugieren algún tipo de transporte de materiales, en las que se puede ver como el punto b está en lo que parece ser la pared de un cráter de impacto, mientras que el punto a se encuentra en una zona más elevada. Comprobamos de nuevo en la Figura 22 lo postulado, los centros de banda que más se desplazan a la izquierda corresponden a regiones que se encuentran en las paredes de los cráteres por hallarse allí material excavado por la colisión.

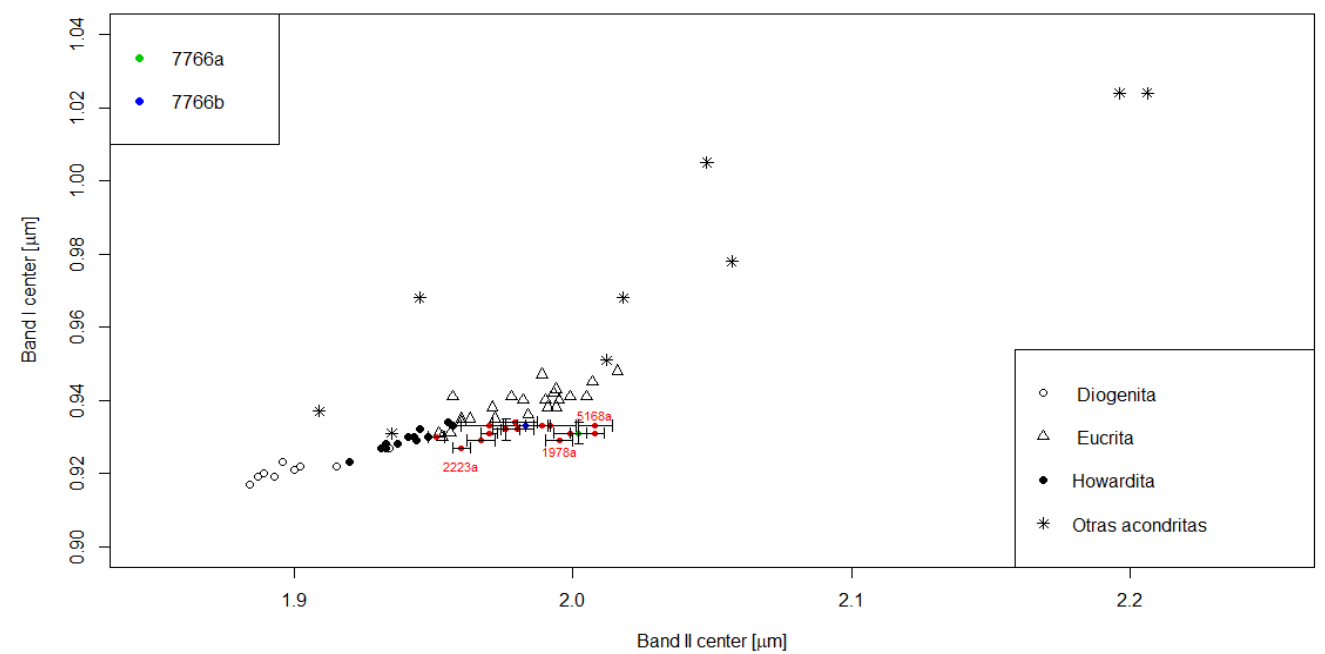

Figura 22. Centro de banda I frente al centro de banda II donde se muestran los puntos estudiados con sus errores y los HED. Se encuentran resaltados los puntos pertenecientes a la imagen 7766. 
Por último, en la imagen 1002 el punto a se encuentra en la pared de un cráter profundo, el b en las afueras de este primer cráter y el $\mathrm{c}$ en la pared de un cráter no tan profundo. Para esta imagen si se puede ver en la Figura 23 claramente como los puntos a y b se encuentran mucho más desplazados a la izquierda que el c, este resultado se debe a que se esta tratando con dos cráteres diferentes uno de los cuales es más profundo, y por tanto, ha excavado material de capas más internas de la corteza. Dentro de los dos puntos correspondientes al cráter profundo, que el que se encuentra fuera del cráter tenga centros de banda tan pequeños en comparación con los de la pared del cráter puede indicar la presencia de material eyectado a causa del impacto aunque el gran error asociado a $1002 \mathrm{~b}$ no permite afirmarlo.

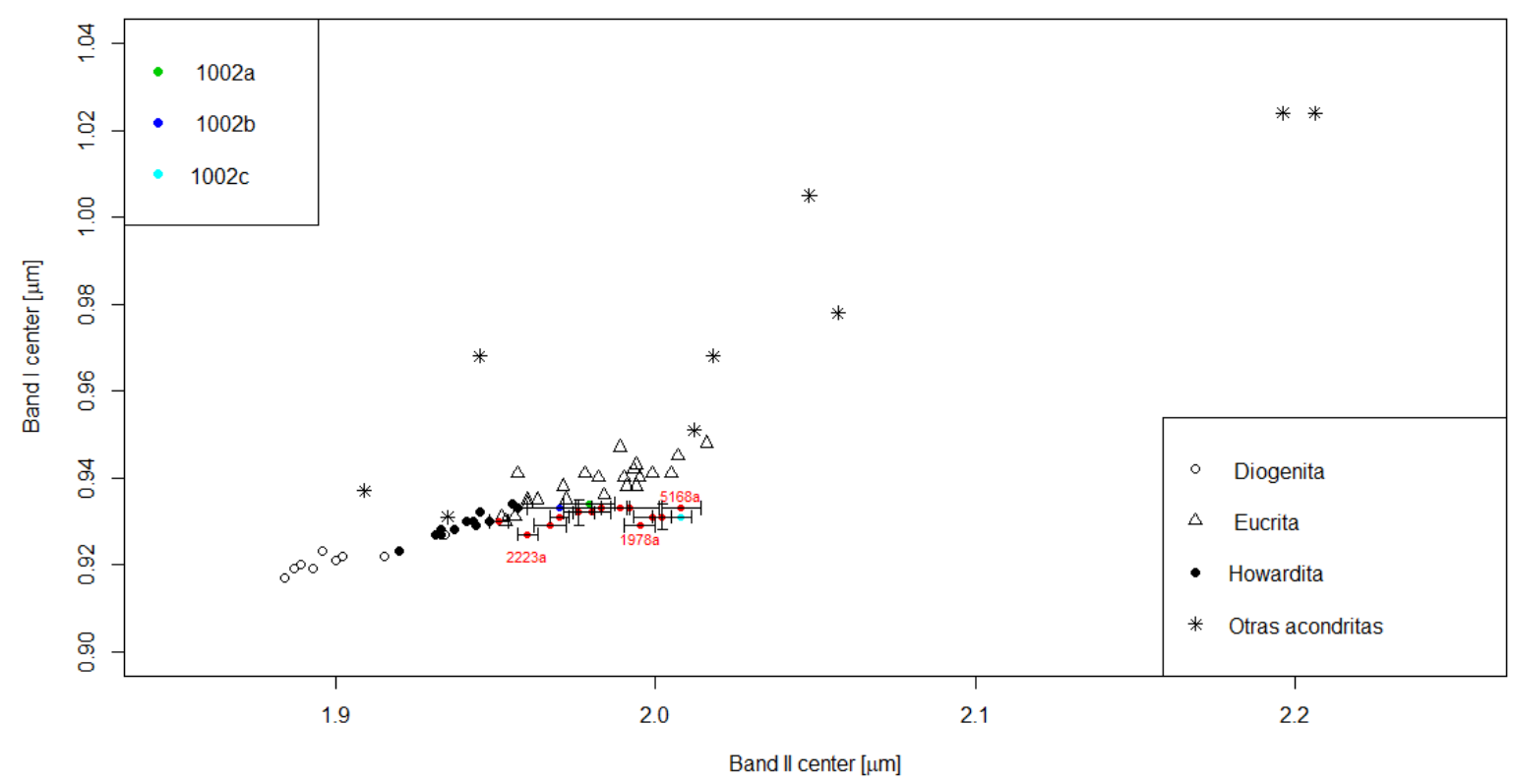

Figura 23. Centro de banda I frente al centro de banda II donde se muestran los puntos estudiados con sus errores y los HED. Se encuentran resaltados los puntos pertenecientes a la imagen 1002.

\section{Conclusiones}

El trabajo realizado ha tenido como objetivo principal el estudio de Vesta a partir de los datos proporcionados por el espectrometro VIR de la sonda Dawn enviada por la Nasa el pasado 2007. Estos datos en el formato característico de las misiones planetarias son públicos y pueden encontrarse en la página (Vesta VIR, 2020). Ha sido necesario su procesamiento a través de distintos programas en base Linux para poder visualizarlos en forma de imágenes infrarrojas y visibles. Este proceso se ha realizado para un total de 6 imágenes de la superficie de Vesta, recopiladas en el Anexo. Tras esto se procedió a la obtención y procesamiento de los espectros de cada uno de los 16 puntos de la superficie de Vesta reflejados en las imágenes anteriores. Como resultado se han obtenido los espectros de todos estos puntos listos para el análisis de la composición mineralógica de Vesta a través de ellos y sus parámetros asociados, como son los mínimos y centros de banda y la profundidad de banda. El principal propósito una vez alcanzados los resultados era comparar los centros de banda, definidos como la posición de la longitud de onda del punto de reflectancia más baja después de la eliminación del continuo o tendencia del espectro, con los de los HED, meteoritos que se creen procedentes de Vesta. Con dos fines principales la 
evaluación de si podrían tener como cuerpo parental a Vesta como la mayoría de estudios apuntan y siendo así, el análisis de las regiones estudiadas por comparación con estos.

Tras los resultados obtenidos se concluye que los HED con gran probabilidad provendrían de Vesta, ya que los centros de banda de las regiones analizadas se asemejan enormemente a los de los HED, salvo en una pequeña desviación en la pendiente que toman, que se encuentra igualmente en otros estudios (McSween et al., 2013) y puede ser explicada con algunos factores que alteran levemente los resultados, como son el tamaño de los meteoritos analizados, la meteorización espacial y la temperatura del laboratorio donde se analizan. Además, la comparación con los HED concuerda con los resultados obtenidos, pues los centros de banda de las zonas estudiadas que se encuentran más desplazadas hacia las howarditas, el 1768b y 2223a de la Figura 17, pertenecen a las zonas situadas en las paredes de grandes cráteres jóvenes que, como se demuestra en el estudio (De Sanctis et al., 2013), es donde se puede encontrar más material brillante (con un albedo mayor), asociado a material fresco perteneciente a capas subyacentes que ha sido expuesto por colisiones. Este material fresco se caracteriza por espectros con profundidades de banda mayores, y observando la Figura 12 se puede ver como las diogenitas poseen mayor profundidad de banda que las howarditas y estás a su vez mayor que las eucritas. Por lo que este resultado corrobora la diferenciación que ha sufrido Vesta, ya que el hecho de que materiales más frescos estén asociados a profundidades de banda mayores se atribuye a la presencia de una corteza superficial de eucrita e interna de diogenita, siendo la howardita una mezcla de ambas.

Otras constataciones realizadas para la información que se encuentra en los estudios actuales sobre Vesta ha sido comprobar como la mayoría de los centros de banda de los espectros analizados muestran que la corteza de Vesta es primordialmente eucrítica formada por ortopiroxeno (bajo en calcio), el efecto en los espectros de la geometría de observación (ángulos de incidencia y emisión para los que se toman las imágenes) y la presencia de una menor proporción de calcio en los piroxenos asociados a zonas con centros de banda menores. 


\section{$\underline{\text { Anexo }}$}

En el anexo que sigue se mostraran las imágenes de la superficie de Vesta utilizadas para el rango infrarrojo y visible del VIR y la misma imagen obtenida por la cámara visible (FC) que aporta mayor resolución. También se podrá ver la localización de la superficie de Vesta donde han sido tomadas las imágenes.

\section{$\underline{\text { HAMO }}$}

\section{CICLO 2-1978}

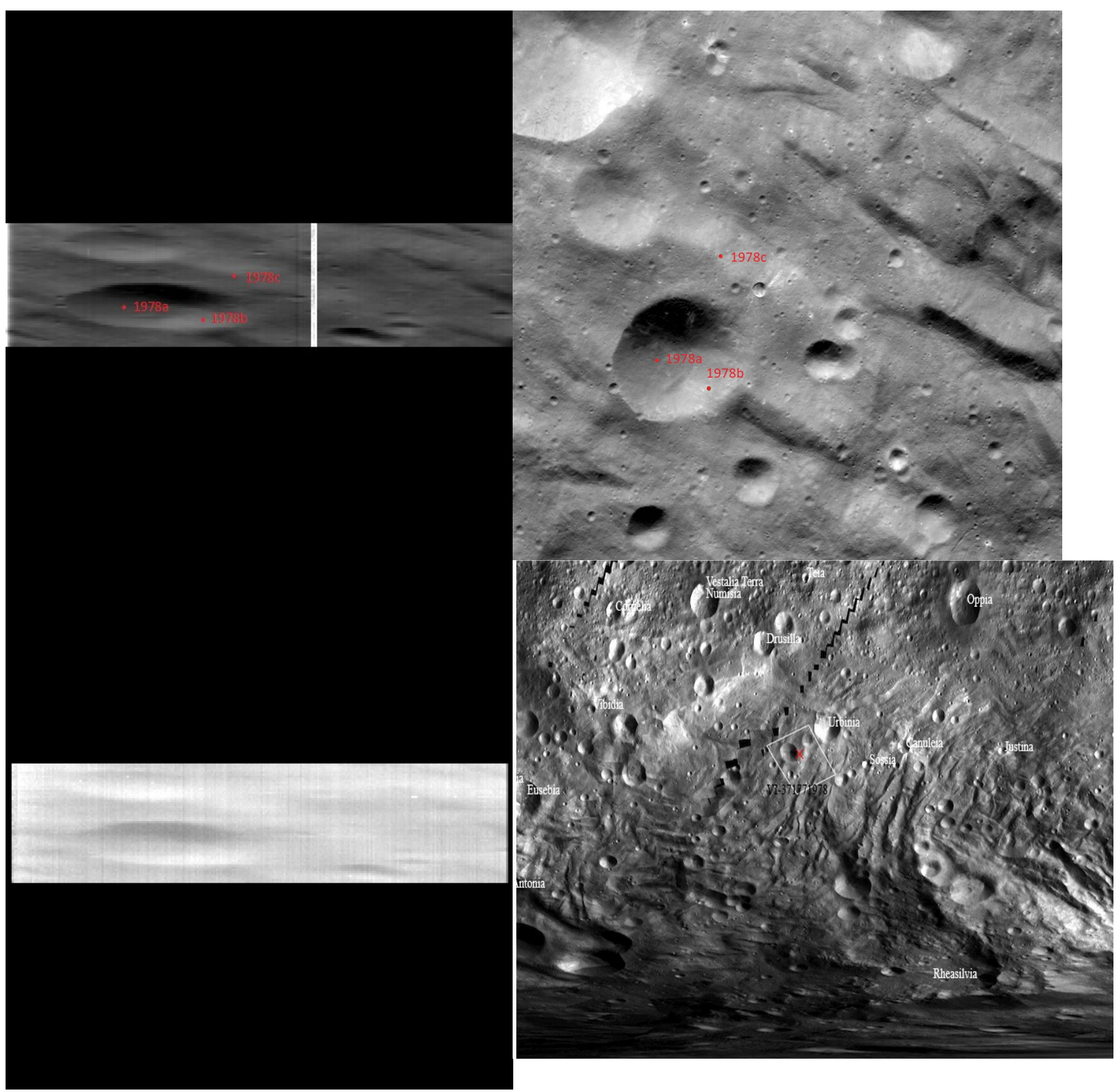

Figura 1: A la izquierda tenemos las imágenes 1978obtenidas por el instrumento VIR en el espectro infrarrojo y visible respectivamente. A la derecha, la imagen 1978 realizada por la cámara de imágenes FC de la misma región de Vesta y debajo la posición relativa de esa región en la superficie del asteroide. Se muestra con puntos rojos las ubicaciones donde se han tomado los espectros de la imagen. 


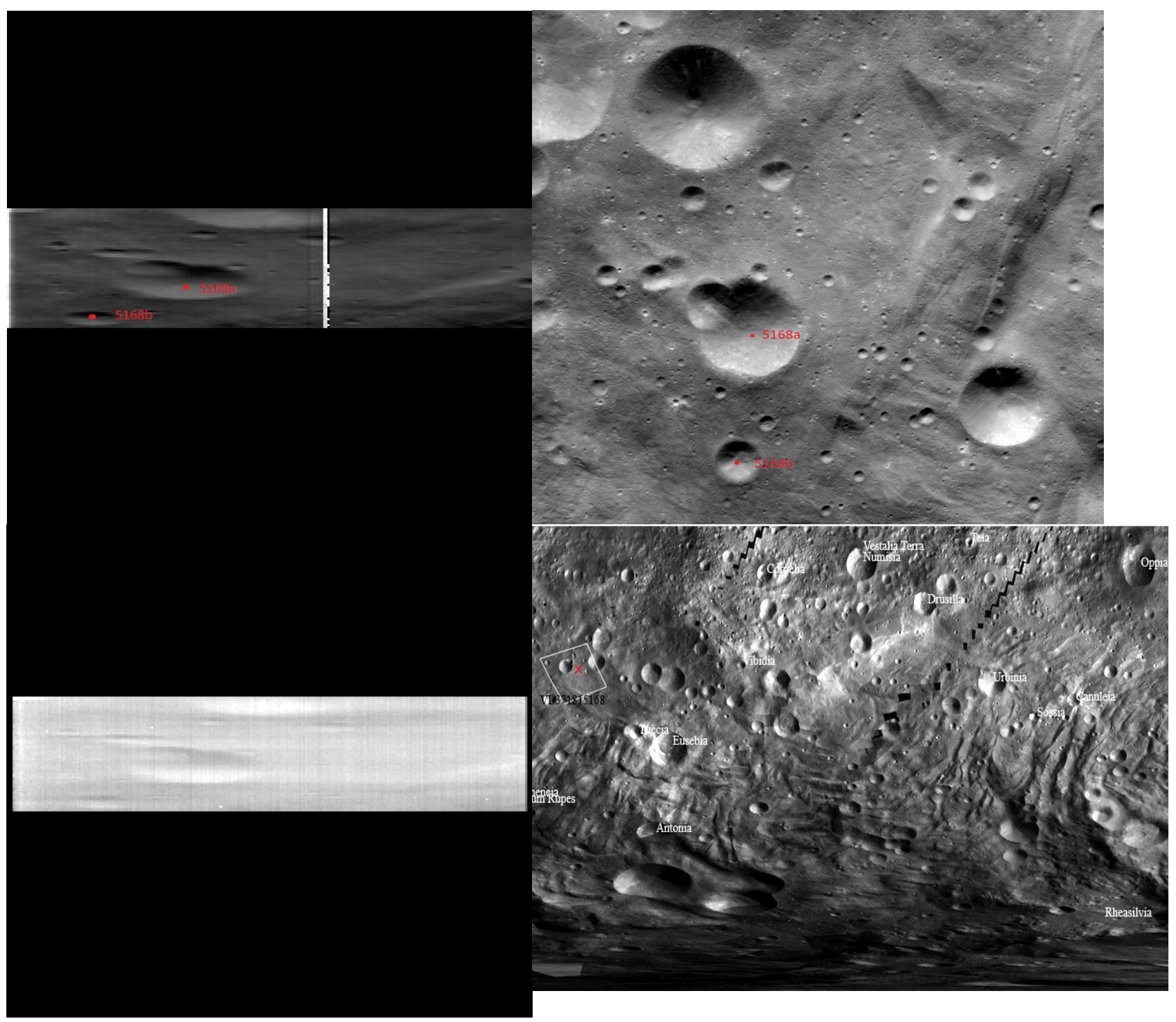

Figura 2: A la izquierda tenemos las imágenes 5168obtenidas por el instrumento VIR en el espectro infrarrojo y visible respectivamente. A la derecha, la imagen 5168 realizada por la cámara de imágenes FC de la misma región de Vesta y debajo la posición relativa de esa región en la superficie del asteroide. Se muestra con puntos rojos las ubicaciones donde se han tomado los espectros de la imagen. 


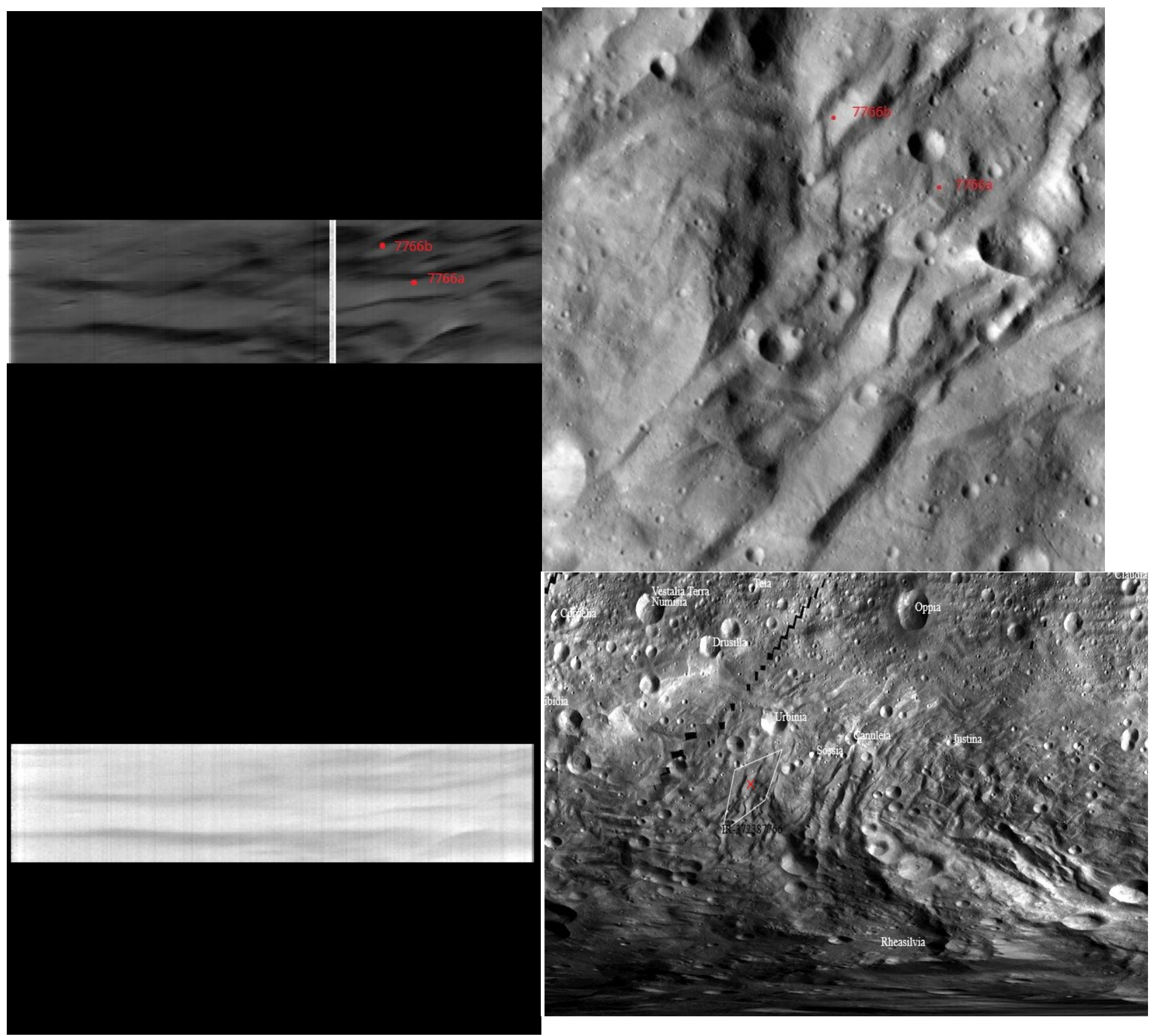

Figura 3: A la izquierda tenemos las imágenes 7766 obtenidas por el instrumento VIR en el espectro infrarrojo y visible respectivamente. A la derecha, la imagen 7766 realizada por la cámara de imágenes FC de la misma región de Vesta y debajo la posición relativa de esa región en la superficie del asteroide. Se muestra con puntos rojos las ubicaciones donde se han tomado los espectros de la imagen. 


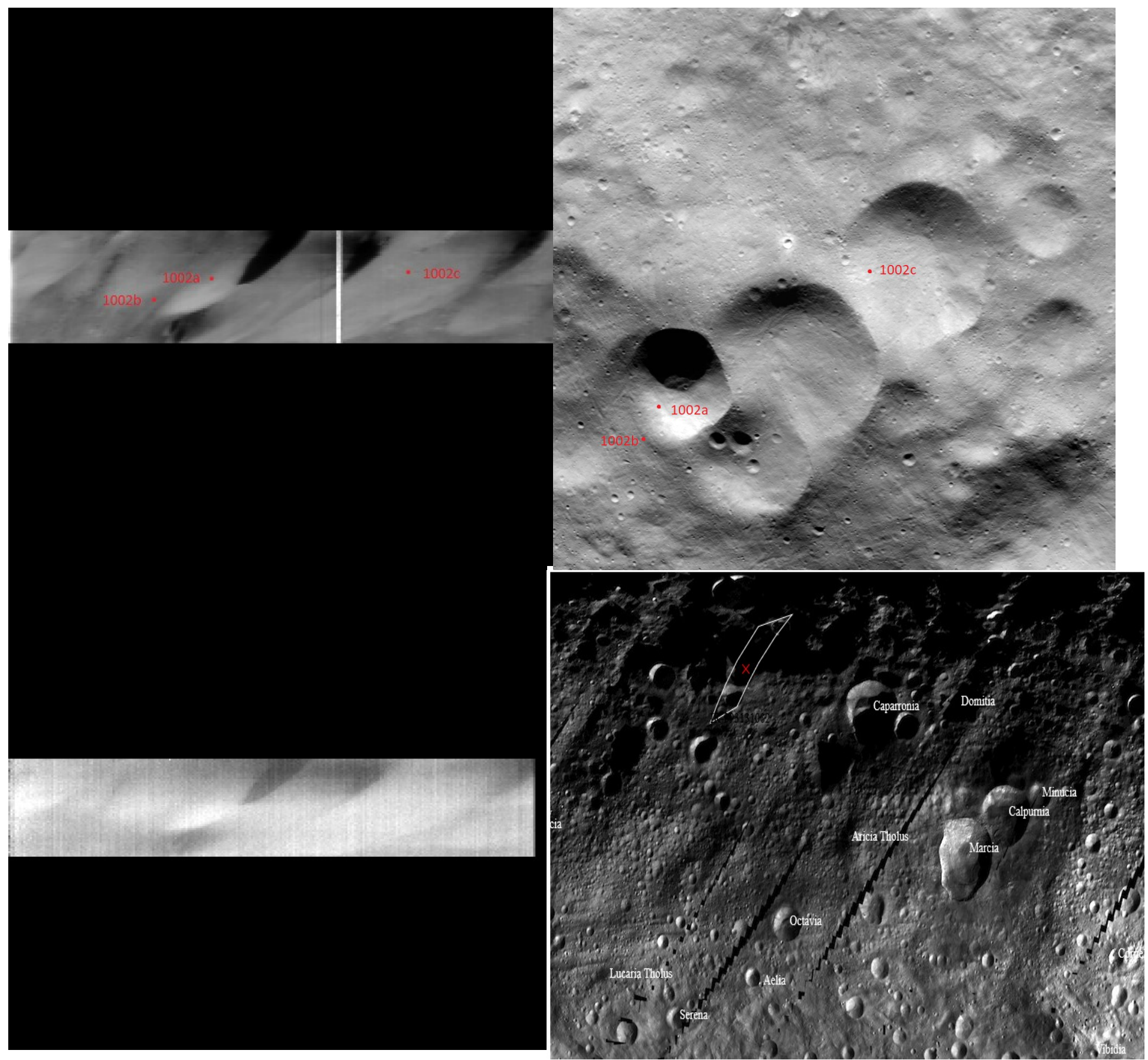

Figura 4: A la izquierda tenemos las imágenes 1002 obtenidas por el instrumento VIR en el espectro infrarrojo y visible respectivamente. A la derecha, la imagen 1002 realizada por la cámara de imágenes FC de la misma región de Vesta y debajo la posición relativa de esa región en la superficie del asteroide. Se muestra con puntos rojos las ubicaciones donde se han tomado los espectros de la imagen. 


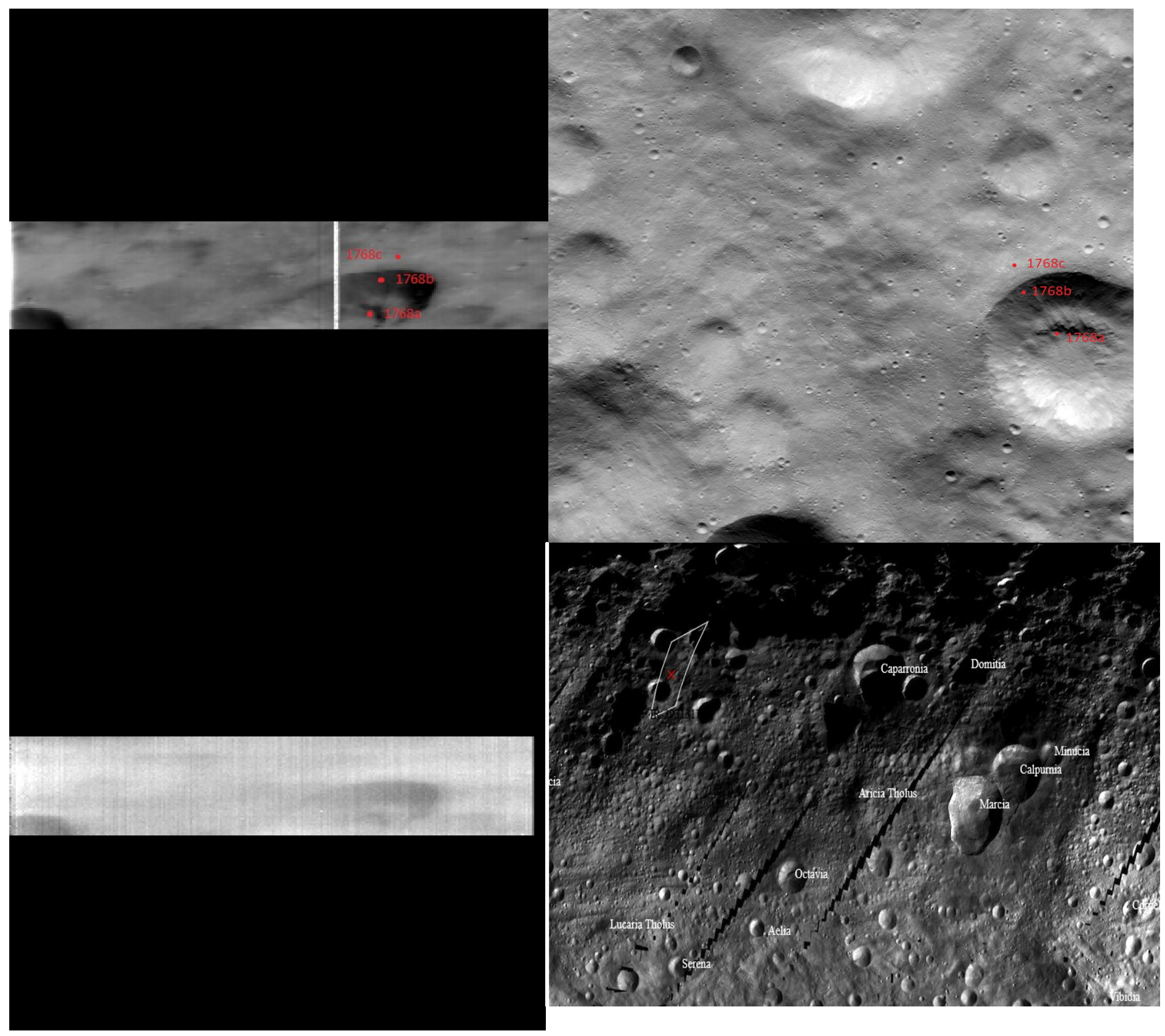

Figura 5: A la izquierda tenemos las imágenes 1768 obtenidas por el instrumento VIR en el espectro infrarrojo y visible respectivamente. A la derecha, la imagen 1768 realizada por la cámara de imágenes FC de la misma región de Vesta y debajo la posición relativa de esa región en la superficie del asteroide. Se muestra con puntos rojos las ubicaciones donde se han tomado los espectros de la imagen. 


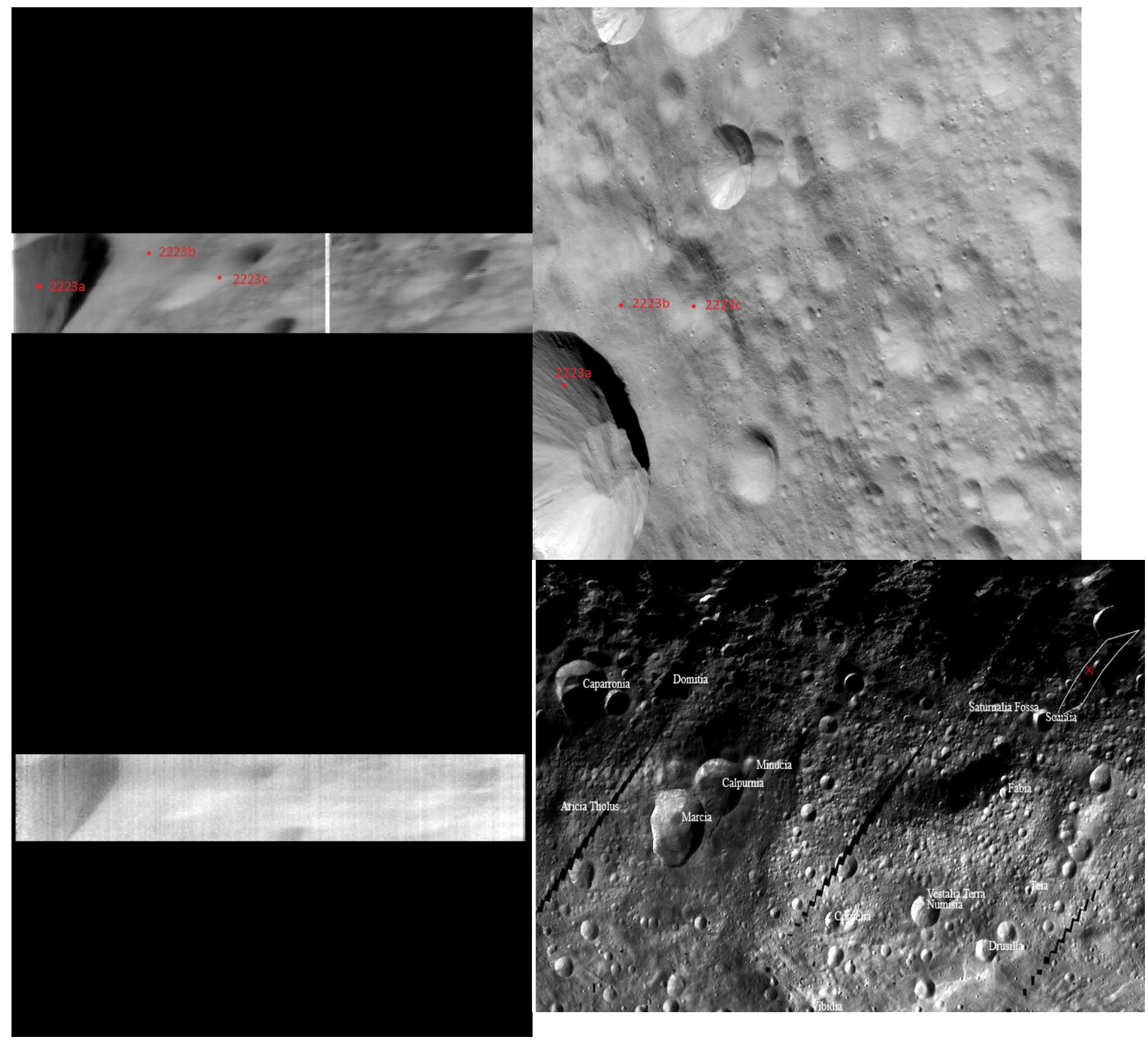

Figura 6: A la izquierda tenemos las imágenes 2223 obtenidas por el instrumento VIR en el espectro infrarrojo y visible respectivamente. A la derecha, la imagen 2223 realizada por la cámara de imágenes FC de la misma región de Vesta y debajo la posición relativa de esa región en la superficie del asteroide. Se muestra con puntos rojos las ubicaciones donde se han tomado los espectros de la imagen. 


\section{$\underline{\text { Referencias }}$}

Ammannito E, De Sanctis MC, Capaccioni F, Teresa Capria M, Carraro F, Combe JP, et al. Vestan lithologies mapped by the visual and infrared spectrometer on Dawn. Meteorit Planet Sci 2013;48:2185-98. https://doi.org/10.1111/maps.12192.

Binzel RP, Gaffey MJ, Thomas PC, Zellner BH, Storrs AD, Wells EN. Geologic mapping of Vesta from 1994 Hubble Space Telescope images. Icarus 1997;128:95-103.

https://doi.org/10.1006/icar.1997.5734.

Capria MT. VIR STANDARD DATA PRODUCTS AND ARCHIVE VOLUME SOFTWARE INTERFACE SPECIFICATION 2018.

https://sbnarchive.psi.edu/pds3/dawn/vir/DWNC1VIR_V1A/DOCUMENT/SIS/

DAWN_VIR_SIS_V1_12.HTM\#_section $($ accessed August 18, 2020).

Duffard R. Mineralogy of Basaltic Material on the Minor Bodies of Our Solar System. An Introd to Study Mineral 2012. https://doi.org/10.5772/35808.

Duffard R, Lazzaro D, De León J. Revisiting spectral parameters of silicate-bearing meteorites. Meteorit Planet Sci 2005;40:445-59. https://doi.org/10.1111/j.1945-5100.2005.tb00393.x.

Duffard R, Lazzaro D, Licandro J, De Sanctis MC, Capria MT, Carvano JM. Mineralogical characterization of some basaltic asteroids in the neighborhood of (4) Vesta: First results. Icarus 2004;171:120-32. https://doi.org/10.1016/j.icarus.2004.05.004.

GitHub - USGS-Astrogeology/ISIS3: Integrated Software for Imagers and Spectrometers v3. 2020. https://github.com/USGS-Astrogeology/ISIS3 (accessed August 18, 2020).

McCord TB, Sotin C. Ceres: Evolution and current state. J Geophys Res E Planets 2005;110:1-14. https://doi.org/10.1029/2004JE002244.

McSween HY, Binzel RP, De Sanctis MC, Ammannito E, Prettyman TH, Beck AW, et al. Dawn; the Vesta-HED connection; and the geologic context for eucrites, diogenites, and howardites. Meteorit Planet Sci 2013;48:2090-104. https://doi.org/10.1111/maps.12108.

Morbidelli A, Lunine JI, O’Brien DP, Raymond SN, Walsh KJ. Building terrestrial planets. Annu Rev Earth Planet Sci 2012;40:251-75. https://doi.org/10.1146/annurev-earth-042711-105319.

NASA - Latest Image of Vesta Captured by Dawn on July 16, 2011. 2011.

Palmer EE. Using ISIS to read VIR cubes into ISIS Step 1 : Install and / or update ISIS Step 2 : Convert the QUB files into ISIS cubes 2014.

PDS: Data Set Information. 2020. https://pds.nasa.gov/ds-view/pds/viewProfile.jsp?dsid=DAWNA-VIR-3-RDR-IR-VESTA-SPECTRA-V2.0 (accessed September 1, 2020).

Planetary GIS: ISIS3 on Windows 10 WSL Ubuntu (Bash). 2020. http://planetarygis.blogspot.com/ 2017/07/isis3-on-windows-10-bash.html (accessed August 18, 2020). 
Raymond CA, Raymond CA. Science Plan Revision B 2015.

Rousseau B, Raponi A, Ciarniello M, Ammannito E, Carrozzo FG, De Sanctis MC, et al. Correction of the VIR-visible data set from the Dawn mission. Rev Sci Instrum 2019;90.

https://doi.org/10.1063/1.5123362.

Rusch O. Geological Evolution of Asteroid Vesta from Dawn Orbital Observations and meteorite Analogs Ottaviano Rüsch PhD dissertation 2015.

Russell C, Raymond C. The Dawn Mission to Minor Planets 4 Vesta and 1 Ceres. 2011.

Russell CT, Coradini A, Christensen U, De Sanctis MC, Feldman WC, Jaumann R, et al. Dawn: A journey in space and time. Planet Space Sci 2004;52:465-89.

https://doi.org/10.1016/j.pss.2003.06.013.

De Sanctis MC, Ammannito E, Capria MT, Capaccioni F, Combe JP, Frigeri A, et al. Vesta's mineralogical composition as revealed by the visible and infrared spectrometer on Dawn. Meteorit Planet Sci 2013;48:2166-84. https://doi.org/10.1111/maps.12138.

De Sanctis MC, Coradini A, Ammannito E, Filacchione G, Capria MT, Fonte S, et al. The VIR spectrometer. Space Sci Rev 2011;163:329-69. https://doi.org/10.1007/s11214-010-9668-5.

Small bodies image browser. 2020. https://sbib.psi.edu/data/PDS-Vesta/pds-vesta.html? (accessed September 1, 2020).

Thangjam G. Mineralogy and Geology of asteroid (4) Vesta from Dawn Framing Camera 2015.

USGS Isis: Glossary. 2020.

https://isis.astrogeology.usgs.gov/documents/Glossary/Glossary.html\#Level0 (accessed August 21, 2020).

USGS Isis: Logical Cube Format Guide. 2020.

https://isis.astrogeology.usgs.gov/documents/LogicalCubeFormatGuide/

LogicalCubeFormatGuide.html (accessed August 21, 2020).

Vesta VIR. 2020. https://sbn.psi.edu/pds/resource/dawn/dwnvvirL1.html (accessed August 18, 2020). 